Western University Scholarship@Western

1980

\title{
The Theory of the Firm: Uncertainty and Choice of Experiments
}

Chin LIm

Follow this and additional works at: https://ir.lib.uwo.ca/economicsresrpt

Part of the Economics Commons

Citation of this paper:

LIm, Chin. "The Theory of the Firm: Uncertainty and Choice of Experiments." Department of Economics Research Reports, 8008. London, ON: Department of Economics, University of Western Ontario (1980). 
ISSN :

ISBN : $\quad 0-7714-0166-3$

THE THEORY OF THE FIRM: UNCERTAINTY

AND CHOICE OF EXPERIMENTS*

by

Chin Lim

March 1980

* This paper is a considerably revised version of Chapter 3 of the author's Ph.D. thesis submitted to Queen's University. The author is indebted to his thesis committee, Richard Harris and Frank Flatters, and also to Douglas Purvis, Hajime Oniki, Lloyd Paquin and Dan Usher for their encouragement during the progress of the thesis. The author is also grateful to an anonymous referee for providing many valuable comments for improvement on the previous drafts. 
ABSTRACT

Th1s paper demonstrates that the firm, facing both Input supply and output demand uncertainty, may adopt varlous classes of strategles varying according to whether (a) input purchase precedes production and output sales or (b) output sales precedes input purchase and production or (c) Input purchase. and output sales are contracted simultaneously. Also, within each behavioral class, strategles may differ according to whether price or quantity is used as the input purchase or output sales ignal. A large set of feasible strategles is therefore generated which includes those discussed in earlier literature as special cases. Furthermore, several Interesting results are obtained regarding relative dominance between strategles both within and across the various behavioral classes. 


\section{INTRODUCTION}

The basic strategy of a firm comprises the fundamental activities of input purchase, production, and output sales. However, the conduct and organization of these activities differ markedly among firms. Some use price signals, whereas others quantity signals, for the purpose of transacting in either the input or output market - Furthermore, some firms order their activities whereby input purchase precedes production and output sales; some order their activities in reverse whereby output sales precedes input purchase and production; and others contract their input purchase and output sales simultaneously. In the face of such a large variety of observed behavior, it is both interesting and desirable to understand the environment by which the various strategies can be generated and, more importantly, to explain why one strategy would dominate another.

The analysis begins by considering a fim which faces uncertainty In both Its output demand and Input supply conditions. In the absence of an omnisclent auctioneer who freely supplies information on trading prices and the fessible set of trades, the firm in such an environment must necessarily transmit its trade signals in order to discover its trade possibilities. We call such an activity a signalling experiment. A coupling of two signalling experiments, one in each market, together with the final transactions form a complete experiment or, equivalently, a behavioral mode.

In the model, three classes of behavioral modes are generated. The first class characterizes a situation in which the firm first experiments (using either a price or quantity signal) in the input market in order to elicit information on the trading preferences of agents in this market before it makes its input purchase and production decisions. It then experiments (again using either a price or quantity signal) in the output market before 
Rothsches d cominal

Hat ?tis

if uitis iffor. dot stives: in Anst $p$ peras wer

sales transactions are conducted. The second class describes a situation where the above sequence of operation is reversed, i.e., the firm first experiments in the output market and secures a sales contract before it conducts its input market experiment to obtain the required input purchase and production in order to satisfy the prior sales contract. Finally, the third class is one in which the firm simultaneously conducts experiments in the input and output markets before the decisions on input purchase, production and sales are finalized. Thus, within each behavioral class, behavioral modes are differentiated according to whether a price or a quantity signal is used in the input or the output market, and across behavioral classes, they are differentiated according to the sequence of experimentation between the input and the output markets.

In the face of the large varlety of observed firm behavior, the purpose of this paper 18: (1) To demonstrate that the above vlewpoint taken at classifying fim behavior provides a useful unifying framework for the understanding of how the large varlety of behavior is generated; and (2) to evaluate the relative dominance of modes both within and across the varlous behavioral classes. The highlights of our results are: F1rst, the behavioral modes discussed in earlier literature, e.g., M11ls [8], Baron [2], Leland [4], LIm [6], and Iwa1 [3], belong to a small subset of the feasible behavloral modes generated in our model. Also, there is absence of Informational advantage $\underline{\underline{b}} \underline{\underline{1}}$ Blackwell (see Marschak and Miyasawa [71) between any two modes both within and across the behavioral classes; hence, behavloral dominance does not trivially depend on the notion of informational superfority. Second, regarding the behavloral dominance within each behavioral class: Except for the singular case of decreasing expected marginal cost in the behavioral class where output sales precedes input purchase and production, quantity signals generally dominate price signals. Third, regarding the 
behavloral dominance between behavioral classes: If uncertainty in the Input market is large relative to that in output market, then the behavioral class where input purchases precedes production and output sales is most preferred, whereas if the converse 1s true, then the most preferred behavioral class Is one where output sales precedes input purchase and production. Finally, Ifm's [6] resulta on the relative dominance among the behavioral modes considered by Baron [2] and Leland [4], which are but special cases of the three of the twelve behavioral modes considered in this model, are now generalized to include the input market uncertainty.

The rest of the paper 1s organized as follows. Section 2 deacribes the Information structure facing the firm. Section 3 postulates the behavioral assumptions by which the various behavioral modes are generated. Section 4 describes the nature of the problem in each behavioral mode. Section 5 analyzes the relative dominance between the modes belonging to each behavloral class. In so dolng, it addresses the 1ssue of price versus quantity decisions withln each behavioral class. Section 6 analyzes the relative dominance between the modes across the different behavloral classes. The issue here is not only the cholce of sequence of experimentation between the Input and output markets but also the cholce between price and quantity decisions. Finally, a sumnary and interpretation of the results are presented in section 7 .

2. INFORMATION STRUCTURE OF THE FIRM

Following Leland [4], the firm is assumed to face a stochastic output demand relation which is expressed in the most general form as the implicit function

$$
F(1) \quad G\left(q^{d}, p^{d}, \eta\right)=0
$$


where $q^{d}$ is quantity demand, $p^{d}$ is demand price, and $\eta_{\varepsilon}[\underline{M}, \bar{M}]$ is a random variable, not known ex ante, which has subjective density $d \Psi(\eta)$. Treating $\mathrm{F}(1)$ as a mapping from a probability space into a set of dowward sloping demand functions, we can place the following restrictions on the 1mplicit function $\mathrm{F}(1)$ : For any given $\eta$, the relation between $q^{d}$ and $p^{d}$ is negative; and that larger values of $\eta$ are associated with larger demand. These restrictions enable us to express $F(1)$ as either

$$
\begin{aligned}
& F(2) \quad q^{d}=q^{d}\left(p^{d}, \eta\right), \quad q_{1}^{d}<0, q_{2}^{d}>0 \\
& \text { or } \quad F(3) \quad p^{d}=p^{d}\left(q^{d}, \eta\right), p_{1}^{d}<0, p_{2}^{d}>0
\end{aligned}
$$

Now define $\eta^{0} \equiv E_{\eta}[\eta]$ and consider two arbitrary values of price, $p_{\alpha}$, and quantity, $q_{\alpha}$. For sufficiently small uncertainty or random fluctuations of $\eta$, expand $q^{d}\left(p_{\alpha}, \eta\right)$ and $p^{d}(q, \eta)$ around $\eta^{\circ}$ as

$$
q^{d}\left(p_{\alpha}, \eta\right) \simeq q^{d}\left(p_{\alpha}, \eta^{o}\right)+q_{2}^{d}\left(p_{\alpha}, \eta^{o}\right) \cdot\left(\eta-\eta^{o}\right)
$$

and $\quad p^{d}\left(q_{\alpha}, \eta\right) \approx p^{d}\left(q_{\alpha}, \eta^{o}\right)+p_{2}^{d}\left(q, \eta^{0}\right) \cdot\left(\eta-\eta^{0}\right)$.

Taking the expectation of the above, and noting $\eta^{0}=E_{\eta}[\eta], E_{\eta}\left[q^{d}\left(p_{\alpha}, \eta\right)\right] \approx q^{d}\left(p_{\alpha}, \eta^{0}\right)$ and $E_{\eta}\left[p^{d}(q, \eta)\right] \approx p^{d}\left(q_{\alpha}, \eta^{0}\right)$. These are accurate approximations if the probability distribution is compact and in which variations in $\eta$ are small (see Samuelson [11]). Now, because $q_{1}^{d}<0$ and $p_{1}^{d}<0$, it follows that for any arbitrary choice of $\mathrm{P}_{\alpha}$ and $\mathrm{q}_{\alpha}$, and for small uncertainty,

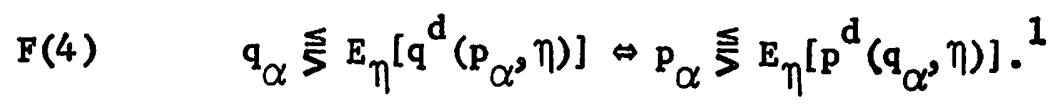

Analogous to the output demand relation, the stochastic input supply function is also written generally as

$$
\mathrm{F}(5) \quad \mathrm{H}\left(\mathrm{n}^{8}, \mathrm{w}^{\mathrm{s}}, \theta\right)=0
$$

where $n^{8}$ is the input supply, $w^{8}$ is the input supply price or wage, and $\theta$ ( $\Theta$, with interval $[\underline{N}, \bar{N}]$, is a random variable, not known ex ante, which 
has subjective density $d \Phi(\theta)$. The restrictions on $F(5)$ is that $n^{8}$ and $w^{8}$ are positively related for any $\theta$, and that larger values of $\theta$ are associated with larger input supply. These restrictions imply that $F(5)$ can be written as either

$\begin{array}{lll} & F(6) & n^{s}=n^{s}\left(w^{s}, \theta\right), n_{1}^{s}>0, n_{2}^{s}>0 \\ \text { or } & F(7) & w^{s}=w^{s}\left(n^{s}, \theta\right), w_{1}^{s}>0, w_{2}^{s}<0 .\end{array}$

Analogous to the output demand relation, it can be easily shown that for any arbitrary choice of wage, $w_{\alpha}$, and input units, $n_{\alpha}$, and for sufficiently small uncertainty,

$$
F(8) \quad n_{\alpha} \lesseqgtr E_{\theta}\left[n^{s}\left(w_{\alpha}, \theta\right)\right] \Leftrightarrow w_{\alpha} \gtreqless E_{\theta}\left[w^{s}\left(n_{\alpha}, \theta\right)\right] .
$$

In addition, it is assumed that $\theta$ and $\eta$ are independently distributed, ${ }^{2}$ i.e., the joint distribution

$$
F(9) \quad \Gamma(\theta, \eta)=\Phi(\theta) \cdot \Psi(\eta)
$$

Finally, the firm is assumed to know its production function

$$
F(10) \quad q=f(n), \quad f^{\prime}(n)>0
$$

with certainty, where $q$ is output and $n$ is the input employed.

\section{BEHAVIORAL ASSUMPTIONS}

The information structure $F(\cdot)$ merely describes the firm's perception of its environment and technology. By itself it does not convey how uncertainty in its output demand and input supply conditions are resolved. Clearly, the behavior of the firm depends critically on the learning mechanism it employs to resolve its uncertainty. In what follows, we postulate the assumptions by which various behavioral modes are generated.

$A(1)$ : The revelation of the stochastic variables $\eta$ and $\theta$ is not dependent on time.

This rules out the degenerate case where the uncertainty problem disappears by simply having the firm waiting till $\eta$ and $\theta$ reveal themselves. In other words, the firm has to always contend with a state of imperfect knowledge unless it does the following. 
$A(2):$ The necessary condition for the resolution of uncertainty in the output demand and input supply conditlons is that the firm conducts the following s1gnaling experiments: In the output market, it must efther signal a supply price, $p^{8}$, or quantity supply, $q^{8}$; and in the Input market, it must either signal a demand wage, $w^{d}$, or input demand, $\mathbf{n}^{\mathrm{d}}$.

In the absence of an omnisclent auctioneer who freely supplies Information on trading prices and the feasible set of quantity trades, the burden of discovering these rests with the traders themselves. In order to discover 1ts trade possibilities, therefore, the fim must necessarily transmit 1ts trade offer so as to eliclt a trade response from 1 ts trading agents.

We call the transmission of such Information a signal. A signal can elther be a price or quantity so that the supply signal variable in the output market is either the supply price, $p^{8}$, or quantity supply, $q^{8}$; and the demand signal in the input market is either the demand wage, $w^{d}$, or the Input demand, $\mathrm{n}^{\mathrm{d}}$.

The purpose of a signal 18, of course, to elicit a trade response. Such a signal/response relationship is termed a signalling experiment, and the result of which is to establish two pleces of information necessary for trade. Firstly, it establishes the trading price and secondly, it defines the feasible set of quantity trades.

Denoting the symbol $\rightarrow$ as a signel/response relationshlp, the signalling experiment in the output market could be either

$$
\text { or } \quad \begin{aligned}
p^{s} & \rightarrow q^{d}\left(p^{s}, \eta\right) \\
q^{s} & \rightarrow p^{d}\left(q^{s}, \eta\right)
\end{aligned}
$$


In (3.1), the supply price signal $\mathrm{p}^{8}$ serves also as the trading price set ex ante $(T)$ by the firm and the feasible set of output quantity trades is defined by the response $q^{d}\left(p^{8}, \eta\right)$ which is the maximum quantity demand reglotered ex post $(\eta)$ at the set price. Alternatively, if the quantity supply signal $q^{8}$ is used as In (3.2), then the trading price 1s the ex post $(T)$ demand price ${ }^{3}$ response $p^{d}\left(q^{8}, \eta\right)$ and the feasible set of quantity trades is also defined since $p^{d}\left(q^{8}, \eta\right)$ is the price at which $q^{8}$ or less is demanded. Simllarly, In the Input market, the signalling experiment could be either

$$
\begin{aligned}
& w^{d} \rightarrow n^{s}\left(w^{d}, \theta\right) \\
& \text { or } \quad n^{d} \rightarrow w^{s}\left(n^{d}, \theta\right) .
\end{aligned}
$$

In (3.3), the demand wage signal $w^{d}$ serves also as the trading price set ex ante $(\theta)$ by the firm and the feasible set of Input quantity trades 18 defined by the response $n^{8}\left(w^{d}, \theta\right)$ which is the maximum avallable input supply reglstered ex post $(\theta)$ at the set price. Alternatively, if the input quantity demand signal $\mathrm{n}^{\mathrm{d}}$ is used as in (3.4), then the trading wage is none other than the ex.post $(\theta)$ supply wage ${ }^{4}$ response $w^{3}\left(n^{d}, \theta\right)$ and the feasible set of Input trades is also defined since $w^{8}\left(n^{d}, \theta\right)$ Indicates the wage at which $\mathrm{n}^{\mathrm{d}}$ or 1 ess 18 supplied.

$A(3)$ S Sequential signaling experimentation is ruled out because of prohibltively high experimental costs.

Now suppose sequential signaling experimentation in each market 1s ruled out because of prohibitively high experimental costs so that the firm in each market is restricted to a single signaling experiment. Then it is necessary that each experiment constitutes an actual bilateral trade offer on which basis actual transactions are conducted. An experiment Is therefore used here only as a heuristic device to illuminate the nature of the firm's real decision rule under uncertainty. 
A(4): The nature of feasible contracts ex post to each signalling experiment.

A transaction is characterized basically by a contract specifying a transacting price and quantity. Let $q$ and $n$ be the feasible quantity transactions in the output and input markets respectively. Then the fearsible contracts ex post to the signalling experiments in (3.1) to (3.4) are respectively,

$$
\begin{aligned}
& \left(p^{8}, q\right) \text { where } q \leq q^{d}\left(p^{8}, \eta\right), \\
& \left(p^{d}\left(q^{8}, \eta\right), q\right) \text { where } q \leq q^{8}, \\
& \left(w^{d}, n\right) \text { where } n \leq n^{8}\left(w^{d}, \theta\right), \\
& \left(w^{8}\left(n^{d}, \theta\right), n\right) \text { where } n \leq n^{d} .
\end{aligned}
$$

The feasible contracts corresponding to the price signalling experiments are Immediately apparent. In experiment (3.1): $p^{s} \rightarrow q^{d}\left(p^{8}, \eta\right)$, the signal $p^{8}$ also serves as the transacting price, and the response $q^{d}\left(p^{8}, \eta\right)$ defines the maximum available demand reglatered ex post $(\eta)$ at price $p^{s}$; hence contract (3.1)'. In experiment (3.3): $w^{d} \rightarrow n^{8}\left(w^{d}, \theta\right)$, the signal $w^{d}$ represents also the transacting wage, and the response $n^{8}\left(w^{d}, \theta\right)$ defines the maximum input supply registered ex post $(\theta)$ at wage $w^{d} ;$ hence contract $(3.3)^{\prime}$.

When quantity signalling experiments are used, however, the nature of their corresponding feasible contracts are as follows. In experiment (3.2): $q^{s} \rightarrow p^{d}\left(q^{8}, \eta\right)$, the signal $q^{d}$ is the ex ante $(\eta)$ offer of quantity supply. But since the ex post $(\eta)$ demand price response $p^{d}\left(q^{s}, \eta\right)$ registers the transacting price at which $q^{8}$ or less is demanded, the firm in the ex post ( $\eta$ contract $(3.2)^{\prime}$ need not commlt itself to sell according to 1ts algnal $q^{8}$, but may entertain a transaction $q<q^{8}$ if. for instance $p^{d}\left(q^{8}, \eta\right)$ turns out to be too low. Similarly, in experiment (3.4): $n^{d} \rightarrow w^{8}\left(n^{d}, \theta\right)$, the 
signal $\mathrm{n}^{\mathrm{d}}$ is the amount of input it offers to purchase ex ante $(\theta)$. But since the ex post $(\theta)$ supply wage response $w^{8}\left(n^{d}, \theta\right)$ represents the transacting wage at which $\underline{n}^{d}$ or less is supplied, the firm in the ex post ( $\theta$ ) contract $(3.4)^{\prime}$ need not commit 1tself to purchase at an Input level according to its signal $n^{d}$, but may entertain a transaction $n<n^{d}$ if for instance $w^{8}\left(n^{d}, \theta\right)$ turns out to be too high.

In all the above contracts, $(3.1)^{\prime}$ to $(3.4)^{\prime}$, the transacting price In each contract is established either by the firm as a price oignal (if a price signalling experiment is used), or by the response price (if a quantity signalling experiment is used). Assumption A(3) rules out the possibility of trading at prices other than the single price observation revealed within the single experiment.

$A(5):$ The information structure $F(\cdot)$ does not vary with the type of Bignalling experiment.

The information set $F(\cdot)$ is the only one available to the firm. There is no other. This forms the basis by which we can legitimately analyze the relative dominance of various experiments.

$A(6)$ : An experiment is chosen to maximize expected profit ${ }^{5}$ of a firm that produceg a perishable good. 
4. THE FORMAL PROBIEM IN EACH EXPERIMENT

Since the function of a firm is to buy (in the input market) and sell (in the output market), a complete experiment consists of a coupling of two signalling experiments, one conducted in each market. Denoting I (either $\mathbf{n}^{d}$ or $w^{d}$ ) and 0 (either $q^{s}$ or $p^{8}$ ) respectively as an input and output market signal, three classes of experiments can be logically generated and characterized by the following ordered pairs: $(I, 0),(0, I)$ and $\left(\begin{array}{l}I \\ 0\end{array}\right)$.

(a) The class of $(I, 0)$ behavior, which contains four possible experiments in $\left(n^{d}, q^{s}\right),\left(w^{d}, q^{s}\right),\left(n^{d}, p^{s}\right)$, and $\left(w^{d}, p^{s}\right)$, is one where signaling experiment 0 is conducted after experiment $I$ is completed.

(b) The class of $(0, I)$ behavior, which contains experiments $\left(q^{8}, n^{d}\right),\left(q^{8}, w^{d}\right)$, $\left(p^{s}, n^{d}\right)$, and $\left(p^{s}, w^{d}\right)$, is one where signalling experiment $I$ is conducted after experiment 0 is completed.

(c) The class of $\left(\begin{array}{l}I \\ 0\end{array}\right)$ behavior, which contains experiments $\left(\frac{n_{d}^{d}}{d}\right),\left(\begin{array}{l}W_{s}^{d} \\ q\end{array}\right),\left(\begin{array}{l}n_{p}^{d} \\ p\end{array}\right)$, and $\left({ }_{p}^{w} s\right)$, is one where both signaliling experiments $I$ and 0 are conducted simultaneously.

Defining :

ex ante $(\theta)$ or $(\eta)$ variable $\equiv$ a choice variable made prior to the revelation of $\theta$ or $\eta$, and

ex post $(\theta)$ or $(\eta)$ variable $\equiv$ a choice variable made after the revelation of $\theta$ or $\eta$

the formal problem in each class of experiments is described as follows.

\subsection{The $(I, 0)$ Problem}

The $(I, 0)$ behavior can be described as the class of ibuy-then-sell" activities. Faced with uncertainty in both the input supply and output demand conditions, the firm begins its operation by signalling I in the input market. 
Upon receiving a trade response from this market, it then makes its actual input purchase, $n$, which uniquely determines the output leve1, $q$, via the production function. It subsequently signals 0 in the output market in order to transact sales. Now since $I$ is ex ante $(\theta)$ and $(\eta)$ and $n, q$, and 0 are ex post $(\theta)$ but ex ante $(\eta)$ the formal problem, which is to maximize expected profit, is characterized by ${ }^{6}$

$$
\underset{I}{\operatorname{Maximize}} \mathrm{E}_{\theta} \underset{\mathrm{n}, q, 0}{\operatorname{Maximum}} \mathrm{E}_{\eta}[\pi(I, \theta, n, q, 0, \eta)]
$$

The description of each experiment and its formal problem is presented below and also summarized in Table $I$.

(a) $\quad\left(n^{d}, q^{s}\right)$ behavior

In this behavior, note that $q=f(n)$, and $q^{s}=q$, so that the maximizing problem can be reduced to

$$
\underset{n^{d}}{\operatorname{Maximize}} E_{\theta} \underset{n \leq n}{\operatorname{Maximum}} R_{q}(n)-w^{s}\left(n^{d}, \theta\right) \cdot n
$$

where

$$
R_{q}(n) \equiv E_{\eta}\left[p^{d}(f(n), \eta)\right] \cdot f(n)
$$

is the expected revenue product function when quantity, $q^{s}$, is used as the output signal. The solution to the above problem can be found by backward induction from the following two-stage procedure.

(i) Given signal $n^{d}$, and hence the response $w^{s}\left(n^{d}, \theta\right)$, the first stage is to choose $n$ so as to

$$
\underset{n \leq n}{\operatorname{maximize}} R_{q}(n)-w^{s}\left(n^{d}, \theta\right) \cdot n .
$$

It is assumed that

$$
R_{q}^{\prime}(n)>0 \text { and } R_{q}^{\prime \prime}(n) \leq 0 \text { for positive } n \text {. . }
$$

The solution to the above can be generally expressed as 7

$$
n_{a}^{\theta} \equiv n_{a}\left(n^{d}, \theta\right) \leq n^{d} \text { for any } \theta
$$




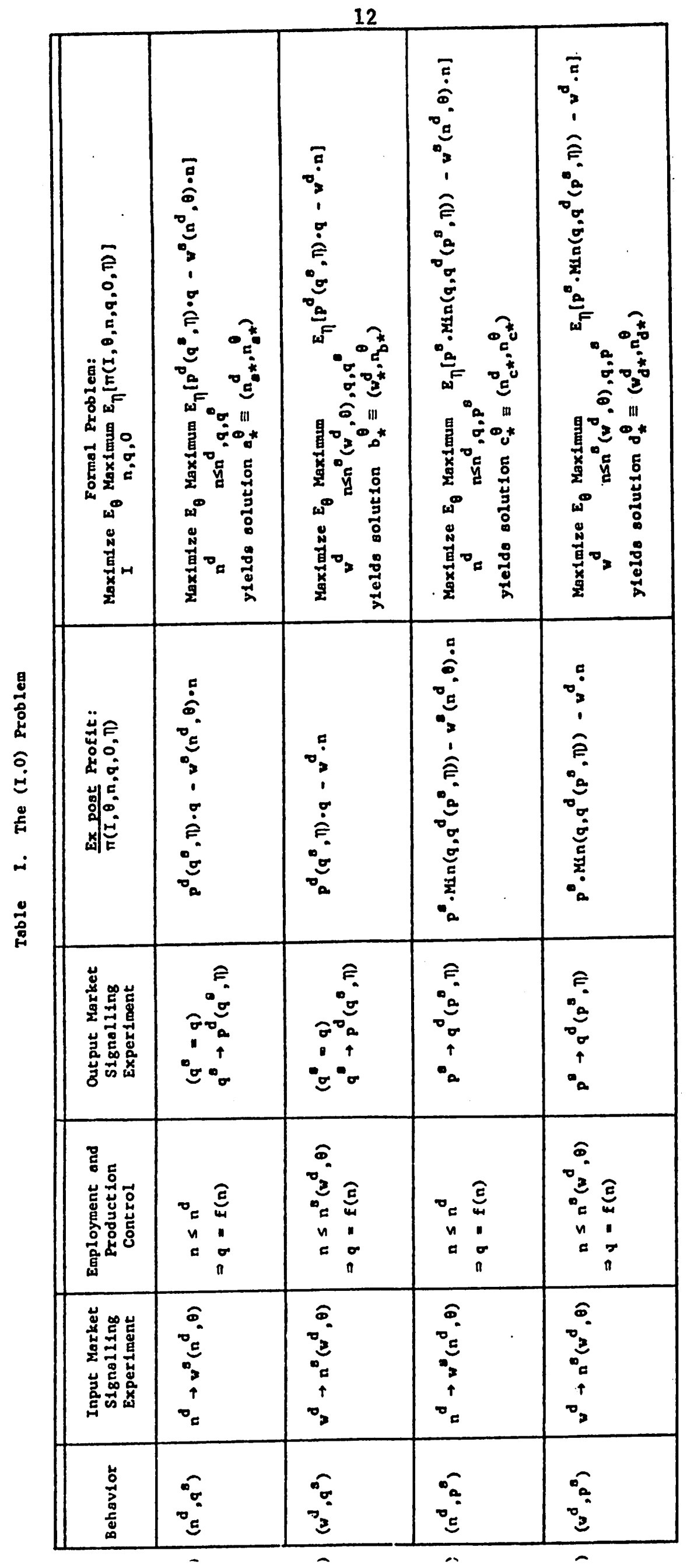


(ii) The next stage is to determine optimal signal $\mathrm{n}^{\mathrm{d}}$. Substituting $n_{a}\left(n^{d}, \theta\right)$ for $n$ in $(4.4)$ and then taking its expectation with respect to $\theta$, optimal $\mathrm{n}^{\mathrm{d}}$ is found as follows.

$$
\underset{n^{d}}{\operatorname{Maximize}} E_{\theta}\left[R_{q}\left(n_{a}\left(n^{d}, \theta\right)\right)-w^{s}\left(n^{d}, \theta\right) \cdot n_{a}\left(n^{d}, \theta\right)\right]
$$

Let $n_{a *}^{d}$ be the solution to (4.7). Then the optimal input purchase is

$$
n_{a *}^{\theta} \equiv n_{a}\left(n_{a *}^{d}, \theta\right) \leq n_{a *}^{d}
$$

The entire solution can be characterized as

$$
a_{*}^{\theta} \equiv\left(n_{a *}^{d}, n_{a *}^{\theta}\right)
$$

and the maximum expected profit

$$
E\left[\pi_{a}\left(a_{*}^{\theta}\right)\right] \equiv E_{\theta}\left[R_{q}\left(n_{a *}^{\theta}\right)-w^{s}\left(n_{a *}^{d}, \theta\right) \cdot n_{a *}^{\theta}\right] \text {. }
$$

(b) $\left(w^{d} q^{s}\right)$ behavior

The maximizing problem in this behavior, which can be reduced to

$$
\underset{w^{d}}{\operatorname{Maximize}} \mathrm{E}_{\theta} \underset{n \leq n^{s}\left(w^{d}, \theta\right)}{\operatorname{Maximum}} R_{q}(n)-w^{d} \cdot n,
$$

is similar to the preceding problem, (4.2), except for the input signal, and the input purchase constraint. Following the two-stage procedure of solving for $w^{d}$ and $n$, the entire solution can thus be generally written as

$$
b_{*}^{\theta} \equiv\left(w_{b *}^{d}, n_{b *}^{\theta}\right)
$$

where $w_{b *}^{d}$ is the optimal demand wage signal and the optimal input purchase

$$
n_{b *}^{\theta} \equiv n_{b}\left(w_{b *}^{d}, \theta\right) \leq n^{s}\left(w_{b *}^{d}, \theta\right) \text { for any } \theta \text {. }
$$

The maximum expected profit

$$
E\left[\pi_{b}\left(b_{*}^{\theta}\right)\right] \equiv E_{\theta}\left[R_{q}\left(n_{b *}^{\theta}\right)-w_{b *}^{d} \cdot n_{b *}^{\theta}\right] .
$$

(c) $\left(n^{d}, p^{s}\right)$ behavior

Using $q \equiv f(n)$, the maximizing problem in this behavior is reduced 


$$
\begin{aligned}
& \underset{n^{d}}{\operatorname{Maximize}} E_{\theta} \underset{n \leq n^{d}, p^{s}}{\operatorname{Maximum}} E_{\eta}\left[p^{s} \cdot \operatorname{Min}\left(f(n), q^{d}\left(p^{8}, \eta\right)\right)-w^{8}\left(n^{d}, \theta\right) \cdot n\right] \\
& =\underset{n^{d}}{\operatorname{Maximize}} E_{\theta} \underset{n \leq n^{d}, p^{s}}{\operatorname{Maximum} R\left(n, p^{s}\right)-w^{s}\left(n^{d}, \theta\right) \cdot n}
\end{aligned}
$$

where $R\left(n, p^{s}\right)$ is the expected sales revenue which can be expressed as either

$$
\begin{aligned}
& R\left(n, p^{8}\right)=p^{s} f(n)+p^{s} \cdot v\left(n, p^{s}\right) \\
& \text { or } \quad R\left(n, p^{s}\right)=p^{s} E_{\eta}\left[q^{d}\left(p^{s} \cdot \eta\right)\right]+p^{s} \cdot s\left(n, p^{s}\right) \\
& \text { where } \quad v\left(n, p^{s}\right) \equiv \int_{\underline{M}}^{\eta *}\left[q^{d}\left(p^{s}, \eta\right)-f(n)\right] d \Psi(\eta) \leq 0 \\
& \text { and } \quad s\left(n, p^{s}\right) \equiv \int_{\eta *}^{\bar{M}}\left[f(n)-q^{d}\left(p^{s}, \eta\right)\right] d \Psi(\eta) \leq 0
\end{aligned}
$$

and where $\eta^{*}$ satisfied $q^{d}\left(p^{s}, \eta *\right)=f(n)$. Note that $V\left(n, p^{8}\right)$ and $s\left(n, p^{8}\right)$ are non-positive for any combination of $n$ and $p^{s} \cdot p^{s} v\left(n, p^{s}\right)$ in (4.16) is the expected loss in revenue due to unsold inventory whenever demand falls short of production. $p^{s} \cdot S\left(n, p^{s}\right)$ in $(4.17)$ is the expected loss in revenue due to foregone potential sales whenever demand exceeds production. Thus (4.16) or (4.17) implies that the expected sales revenue, $R\left(n, p^{8}\right)$, cannot exceed the value of production $p^{s} \cdot f(n)$, or the expected value of demand, $p^{s} \cdot E_{\eta}\left[q^{d} \cdot\left(p^{s}, \eta\right)\right]$, respectively. The solution to problem (4.15), using the two-stage procedure, proceeds as follows.

(i) For any given input signal, $n^{d}$, and the response, $\dot{w}^{s}\left(n^{d}, \theta\right)$, the first stage is to determine $\mathrm{n}$ and $\mathrm{p}^{\mathrm{s}}$. First, to solve for $\mathrm{p}^{\mathrm{s}}$ given $\mathrm{n}$,

$$
\underset{p^{s}}{\operatorname{Maximize}} R\left(n, p^{s}\right)-w^{s}\left(n^{d}, \theta\right) \cdot n \text {. }
$$

Since $p^{s}$ does not appear in the cost term, $w^{s}\left(n^{d}, \theta\right) \cdot n$, the solution to $(4.20)$ can be expressed generally as the expected sales revenue maximizing price, $p^{8}(n)$, for any given $n$. Substituting $p^{8}(n)$ for $p^{8}$ in $(4.20)$, $n$ is then chosen to

$$
\underset{n \leq n^{d}}{\operatorname{Maximize}} R_{p}(n)-w^{s}\left(n^{d}, \theta\right) \cdot n
$$

where $R_{p}(n) \equiv R\left(n, p^{5}(n)\right)$. It is assumed that 


$$
\mathrm{R}_{\mathrm{p}}^{\prime}(\mathrm{n})>0 \text { and } \mathrm{R}_{\mathrm{p}}^{\prime \prime}(\mathrm{n}) \leq 0 \text { for positive } \mathrm{n} \text {. }
$$

The input purchase solution can then be generally expressed as

$$
n_{c}^{\theta} \equiv n_{c}\left(n^{d}, \theta\right) \leq n^{d} \text { for any } \theta \text {. }
$$

(ii) The next stage is to determine $n^{d}$. Substituting $n_{c}\left(n^{d}, \theta\right)$ for $n$ in (4.21) and then taking its expectation with respect to $\theta$, optimal $\mathrm{n}^{\mathrm{d}}$ is found as follows.

$$
\underset{n^{d}}{\operatorname{Maximize}} E_{\theta}\left[R_{p}\left(n_{c}\left(n^{d}, \theta\right)\right)-w^{s}\left(n^{d}, \theta\right) \cdot n_{c}\left(n^{d}, \theta\right)\right] .
$$

Let $n_{c *}$ be the optimal solution to (4.24). Then the optimal input purchase,

$$
n_{c *}^{\theta} \equiv n_{c}\left(n_{c *}^{d}, \theta\right) \leq n_{c *}^{d} \text { for any } \theta
$$

and the entire solution can be written as

$$
c_{*}^{\theta} \equiv\left(n_{c *}^{d}, n_{c *}^{\theta}\right) \text {. }
$$

The maximum expected profit is then

$$
E\left[\pi_{c}\left(c_{*}^{\theta}\right)\right]=E_{\theta}\left[R_{p}\left(n_{c *}^{\theta}\right)-w^{s}\left(n_{c *}^{d}, \theta\right) \cdot n_{c *}^{\theta}\right] .
$$

(d) $\left(w^{d}, p^{s}\right)$ behavior

The maximizing problem in this behavior

$$
\underset{w}{\operatorname{Maximize}} E_{\theta} \underset{n \leq n^{s}\left(w^{d}, \theta\right), p^{s}}{\operatorname{Maximum}} R\left(n, p^{s}\right)-w^{d} \cdot n
$$

is similar to that of $\left(\mathrm{n}^{\mathrm{d}}, \mathrm{p}^{s}\right)$ behavior in (4.15) except for the input signal and the input purchase constraint. Thus, the solution to $(4.28)$ is easily inferred from that of (4.15) and can be generally expressed as

$$
d_{*}^{\theta} \equiv\left(w_{d *}^{d}, n_{d *}^{\theta}\right)
$$

where $w_{d *}^{d}$ is the optimal demand wage signal and the optimal input purchase, 


$$
n_{d *}^{\theta} \equiv n_{d}\left(w_{d *}^{d}, \theta\right) \leq n^{s}\left(w_{d *}^{d}, \theta\right) \text { for any } \theta \text {. }
$$

The maximum expected profit

$$
E\left[\pi_{d}\left(d_{*}^{\theta}\right)\right] \equiv E_{\theta}\left[R_{p}\left(n_{d *}^{\theta}\right)-w_{d *}^{d} \cdot n_{d *}^{\theta}\right] \text {. }
$$

The price adjustment model of Iwai [3] is identically the $\left(w^{d}, p^{8}\right)$ behavior considered above. Also, both the quantity-cum-price setting behavior (originated by Mills [8]) and the quantity setting behavior considered by Baron [2], Leland [4], and Iim [6], although they do not explicitly consider the uncertainty in the input market, are analogous to the above $\left(n^{d}, p^{8}\right)$ and $\left(n^{d}, q^{8}\right)$ behavior respectively. 8

Furthermore, it is important to note that the expected revenue product function, $R_{q}(\cdot)$, which obtains when $q^{8}$ is used as the output signal differs from $R_{p}(\cdot)$ which issues from the experiment where $p^{8}$ is used as the signal. The latter contains the element of potential loss in unsold inventory which Is absent in the former.

\subsection{The $(0, I)$ Problem}

The $(0, I)$ behavior can be described as the class of 'sell-then-buy' activities. Assuming that a forward market exists, the firm begins its operation by announcing its sales signal 0 . Upon receiving a trade response, it then makes its actual sales transaction, $q$, which it seeks to satisfy by purchasing, via the inverse of the production function, the required level of input, n. The input market signal $I$ is therefore constrained by the prior sales contract only to $\mathrm{n}^{\mathrm{d}}(=\mathrm{n})$ since the alternate signal $\mathrm{w}^{\mathrm{d}}$ might give rise to inconsistency whenever the response $n^{s}\left(w^{d}, \theta\right)<n$. Note that in the $(0, I)$ problem, 0 is ex ante $(\eta)$ and $(\theta)$ whereas $q, n$, and $I$ are ex post $(\eta)$ but 
ex ante $(\theta)$ so that the formal problem is characterized as

$$
\underset{0}{\operatorname{Maximize}} E_{\eta} \underset{q, n, I}{\operatorname{Maximum}} E_{\theta}[\pi(0, \eta, q, n, I, \theta)]
$$

The description of each experiment and its formal problem is presented below and also sumnarized in Table II. These experiments can be further simplified because once sales, $q$, is transacted, this uniquely determines the required input signal and employment as $n^{d}=n=f^{-1}(q) \equiv h(q)$ so that the prior sales commitment is satisfied.

(a) $\left(q^{s}, n^{d}\right)$ behavior

The maximizing problem in this behavior can be reduced to

$$
\underset{q^{s}}{\operatorname{Maximize}} E_{\eta} \underset{q \leq q^{s}}{\operatorname{Maximum}} p^{d}\left(q^{s}, \eta\right) \cdot q-c(q)
$$

where $\quad c(q) \equiv E_{\theta}\left[w^{8}(h(q), \theta)\right] \cdot h(q)$

is the expected cost function defined on $q$. Note that $c^{\prime}(q)>0$. The solution to (4.32) is found by the following two-stage procedure:

(i) Given any sales signal, $q^{s}$, and hence the response, $p^{d}\left(q^{s}, \eta\right)$, $q$ is chosen to

$$
\underset{q \leq q^{s}}{\operatorname{Maximize} p^{d}\left(q^{s}, \eta\right) \cdot q-c(q) .}
$$

The solution to $(4.34)$ can be expressed generally as!

$$
q_{a}^{\eta} \equiv q_{a}\left(q^{s}, \eta\right) \leq q^{s} \quad \text { for any } \eta \text {. }
$$

(ii) The next stage is to determine optimal signal, $q^{8}$. Substituting $q_{a}\left(q^{8}, \eta\right)$ for $q$ in $(4.34)$ and then taking its expectation with respect to $\eta, q^{s}$ is chosen to

$$
\underset{q^{s}}{\operatorname{Maximize}} E_{\eta}\left[p^{d}\left(q^{s}, \eta\right) \cdot q_{a}\left(q^{s}, \eta\right)-c\left(q_{a}\left(q^{s}, \eta\right)\right)\right] \text {. }
$$

Let $q_{a *}^{s}$ be the solution to $(4.36)$, then the optimal sales transaction, 


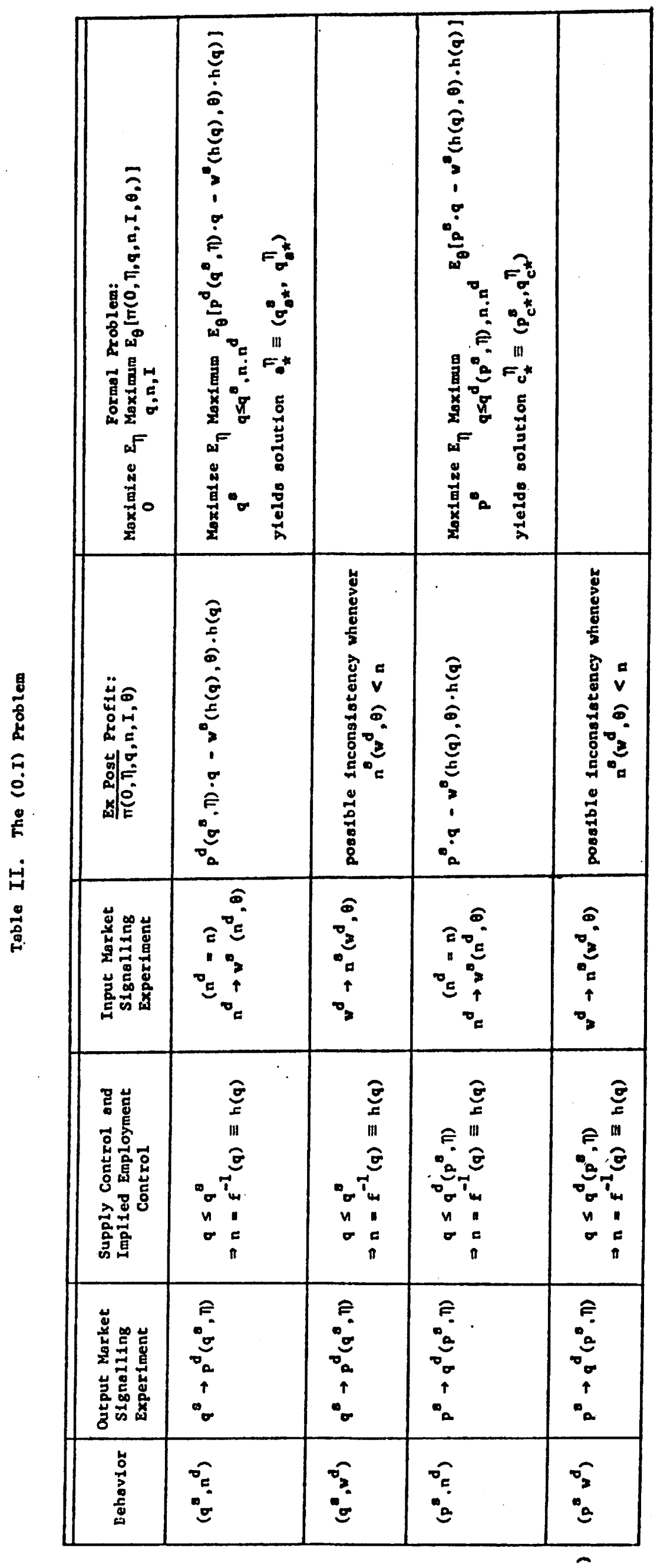




$$
q_{a *}^{\eta} \equiv q_{a}\left(q_{a *}^{8}, \eta\right) \leq q_{a *}^{s} \text { for any } \eta_{0}
$$

The entire solution can be generally written as

$$
a_{*}^{\eta} \equiv\left(q_{a *}^{s}, q_{a *}^{\eta}\right)
$$

and the maximum expected profit

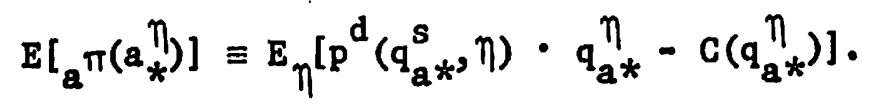

(c) $\left(p^{8} n^{d}\right)$ behavior

The maximizing problem in this behavior

$$
\underset{p^{8}}{\operatorname{Maximize}} E_{\eta} \underset{q \leq q^{d}\left(p^{s}, \eta\right)}{\operatorname{Maximum}} p^{s} \cdot q-C(q)
$$

is similar to (4.32) except for the sales signal and the sales constraint. Thus, the solution to $(4.40)$ is easily inferred from that of (4.32) and can be generally expressed as

$$
c_{*}^{\eta} \equiv\left(p_{c *}^{s}, q_{c *}^{\eta}\right)
$$

where $\mathrm{P}_{c *}^{\mathrm{s}}$ is the optimal supply price signal and the optimal sales,

$$
q_{c *}^{\eta} \equiv q_{c}\left(p_{c *}^{s}, \eta\right) \leq q^{d}\left(p_{c *}^{s}, \eta\right) \text { for any } \eta \text {. }
$$

The maximum expected profit

$$
E\left[c^{\pi}\left(c_{*}^{\eta}\right)\right] \equiv E_{\eta}\left[p_{c *}^{s} \cdot q_{c *}^{\eta}-c\left(q_{c *}^{\eta}\right)\right] \text {. }
$$

The price-setting behavior considered by Baron [2], Leland [4] and Iim [6] is analogous to the $\left(\mathrm{p}^{s}, \mathrm{n}^{\mathrm{d}}\right)$ behavior considered here.

4.3 The $\left(\begin{array}{l}I \\ 0\end{array}\right)$ Problem

The $\left(\begin{array}{l}I \\ 0\end{array}\right)$ behavior can be described as the class of 'buy-and-sell' activities. Both the input signal $I$ and output signal 0 are announced simultaneously. Following the trade responses from both markets, the firm then conducts its output sales, $q$, and the required. input purchase, $n$. Now, both $I$ and 0 are ex ante $(\theta)$ and $(\eta)$ whereas $n$ and $q$ are ex post $(\theta)$ and $(\eta)$ so that the formal problem is to 


$$
\underset{I, 0}{\operatorname{Maximize}} E_{\theta, \eta} \underset{n, q}{\operatorname{Maximum}} \pi(I, 0, \theta, \eta, n, q)
$$

The description of each experiment and its formal problem is summarized in Table III. The solution to each experiment again follows the two-stage procedure utilized previously. As an example, the solution to $\left(\frac{p^{d}}{q}\right)$ is described below.

(A) $\left(\mathrm{n}_{\mathrm{q}}^{\mathrm{d}} \mathrm{s}\right)$ behavior

The solution to this maximizing problem

$$
\underset{n^{d}, q^{s}}{\operatorname{Maximize}} E_{\theta, \eta} \underset{n \leq \operatorname{Min}\left[n^{d}, h\left(q^{s}\right)\right]}{\operatorname{Maximum}} p^{d}\left(q^{s}, \eta\right) \cdot f(n)-w^{s}\left(n^{d}, \theta\right) \cdot n
$$

can be generally written as

$$
A_{*}^{\theta, \eta} \equiv\left(n_{A^{*}}^{d}, q_{A^{*}}^{s}=f\left(n_{A^{*}}^{d}\right), n_{A^{*}}^{\theta, \eta}\right)
$$

where $n_{A^{*}}^{d}$ and $q_{A *}^{s}$ are the optimal signal variables and

$$
n_{A^{*}}^{\theta, \eta} \equiv n_{A^{*}}\left(n_{A^{*}}^{d}, q_{\left.A^{*}, \theta, \eta\right)}^{s} \leq \operatorname{Min}\left[n_{A^{*}}^{d}, h\left(q_{A^{*}}^{s}\right)\right] \text { for any } \theta, \eta,\right.
$$

is the optimal employment. The maximum expected profit

$$
E\left[\pi_{A}\left(A_{*}^{\theta}, \eta\right)\right] \equiv E_{\theta, \eta}\left[p^{d}\left(q_{A^{*}}^{s}, \eta\right) \cdot f\left(n_{A^{*}}^{\theta, \eta}\right)-w^{s}\left(n_{A^{*}}^{d}, \theta\right) \cdot n_{A^{*}}^{\theta, \eta}\right] \cdot(4.48)
$$

The solutions to (B) $\left({ }_{q}^{w} s\right)$, (C) $\left({ }_{p}^{n} s\right)$, and (D) $\left({ }_{p}^{w} s\right)$ behavior are analogous to the above and which differ only in the signals and constraints. Using the appropriate notation, these solutions are adequately summarized in Table III.

From the informational standpoint, there appears to be no apparent advantages between experiments within and across the various behavioral classes. Consider the $(I, 0)$ behavior with its ordered choice vector $(I, \theta, n, q, 0, \eta)$; the $(0, I)$ behavior with 1 ts ordered choice vector $(0, \eta ; q, n, I, \theta)$; and the $\left(\begin{array}{l}I \\ 0\end{array}\right)$ behavior with its choice vector $(I, 0, \theta, \eta, n, q)$. Within each behavioral class, it is 
$<1$

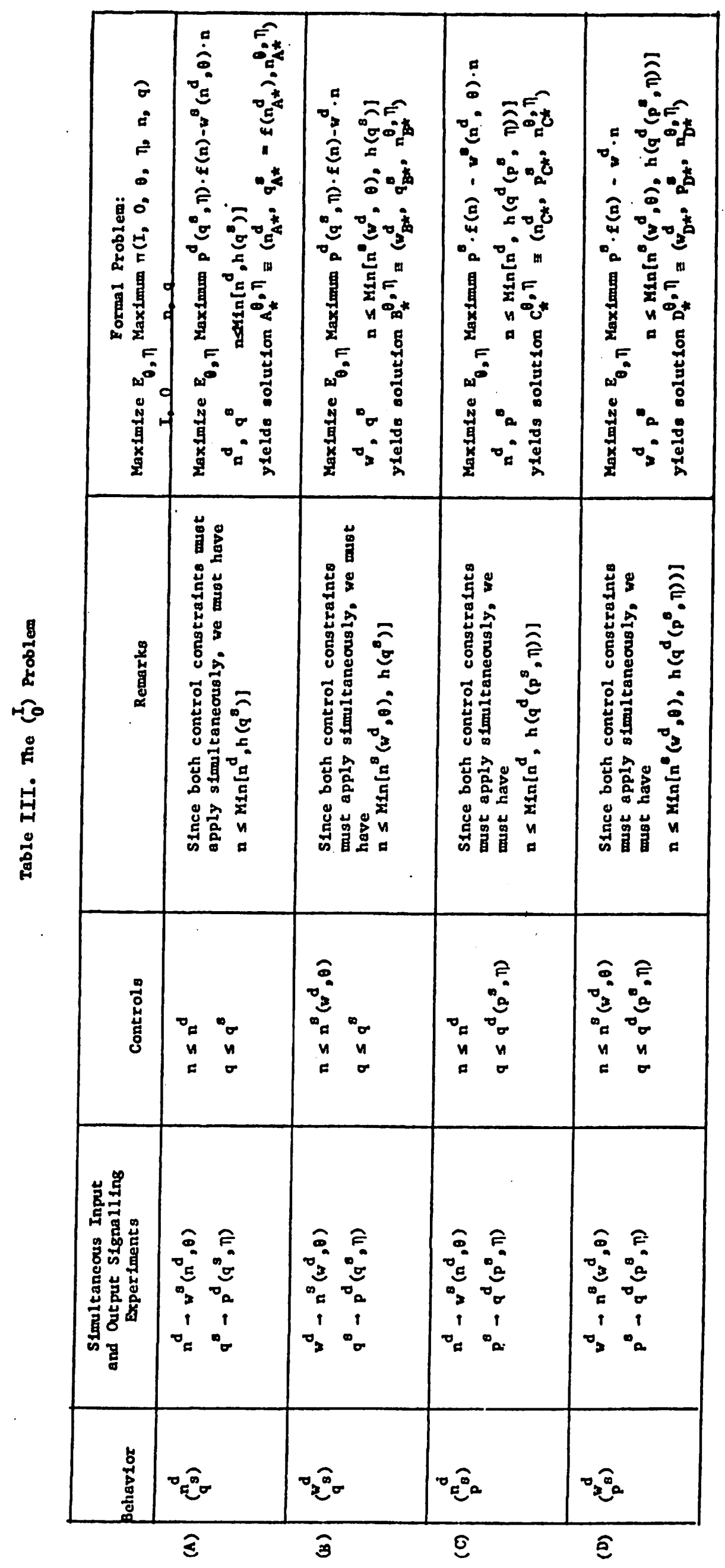


apparent there is no informational advantage between any two experiments since they share an equal number of ex ante and ex post decision variables. Also, any informational advantage between behavioral classes does not seem to exist. This is clear between the $(I, 0)$ and $(0, I)$ behavior since their choice vectors reveal each has to make an equal number of decisions ex ante and ex post. Between the $(I, 0)$ (it suffices to discuss either $(I, 0)$ or $(0, I)$ ) behavior and the $\left(\begin{array}{l}I \\ 0\end{array}\right)$ behavior, the apparent non-existence of informational advantage between them arises as follows. On the one hand, $(I, 0)$ seems to be Informationally superfor over $\left(\begin{array}{l}I \\ 0\end{array}\right)$ because in the latter behavior, two decisions, I and 0 , are made ex ante $(\theta)$ and ex ante $(\eta)$, whereas in the former behavior, only declsion I to ex ante ( $\theta$ ) ant ex ante ( $\eta)$ but decision 0 is ex post $(\theta)$. On the other hand, $(I, 0)$ is informat lonally inferfor to $\left(\begin{array}{l}I \\ 0\end{array}\right)$ because the decisions, $n$ and $q$, In the latter behavior can be made ex post ( $\theta$ ) and ex post ( $\eta)$ whereas In the former behavior, they are made ex post $(\theta)$ but. ex ante ( $(1)$. The absence of Informational advantage between experiments within and across the behavioral classes suggests, therefore, that behavloral dominance cannot, in general, be based trivially on Blackwell's criterion of informational superiority. Instead it relles on other conditions as will be demonstrated in the following sections.

5. RELATIVE DOMINANCE OF WITHIN CLASS EXPERIMENTS

The experiments within each behavioral class are differentiated according to whether quantity or price is used as a market signal. The analysis of choice of within class experiments is therefore a study of comparative advantage between quantity and price signalling experiments.

\subsection{Relative Dominance of Experiments Within the Class of $(I, 0)$ Behavior}

For sufficiently small uncertainty such that $F(4)$ and $F(8)$ hold, the results on the relative dominance of experiments within the $(I, 0)$ class of behavior are as follows. 
Proposition $5.1\left(n^{d}, q^{8}\right)$ behavior is preferred to $\left(n^{d}, p^{8}\right)$ behavior.

Proof :

$\left(n^{d}, p^{s}\right)$ behavior: By definition, $c_{*}^{\theta}=\left(n_{c *}^{d}, n_{c *}^{\theta}\right)$ is optimal. The ex post

$(\theta)$ expected profit in (4.27), after using (4.16) and (4.17), can be expressed

as either

$$
\pi_{c}\left(c_{*}^{\theta}\right)=p^{8}\left(n_{c *}^{\theta}\right) \cdot f\left(n_{c *}^{\theta}\right)+p^{s}\left(n_{c *}^{\theta}\right) \cdot V \cdot\left(n_{c *}^{\theta} p^{8}\left(n_{c *}^{\theta}\right)\right)-w^{8}\left(n_{c *}^{d} \theta\right) \cdot n_{c *}^{\theta}
$$

or $\pi_{c}\left(c_{*}^{\theta}\right)=p^{8}\left(n_{c *}^{\theta}\right) \cdot E_{\eta}\left[q^{d}\left(p^{s}\left(n_{c *}^{\theta}\right), \eta\right)\right]+p^{s}\left(n_{c *}^{\theta}\right) \cdot s\left(n_{c *}^{\theta}, p^{s}\left(n_{c *}^{\theta}\right)\right)-w^{s}\left(n_{c *}^{d}, \theta\right) \cdot n_{c *}^{\theta}$

Now, depending on the nature of demand, cost, and the probability distribution functions, the relationship between optimal supply price, $p^{8}\left(n_{c *}^{\theta}\right)$, and output, $f\left(n_{c *}^{\theta}\right)$, can only take either of the following forms, i.e., (i) $E_{\eta}\left[q^{d}\left(p^{8}\left(n_{c *}^{\theta}\right), \eta\right)\right]$ $z f\left(n_{c^{*}}^{\theta}\right)$ or (ii) $E_{\eta}\left[q^{d}\left(p^{s}\left(n_{c^{*}}^{\theta}\right), \eta\right)\right] \leq f\left(n_{c^{*}}^{\theta}\right)$; which states that for any state of nature $\theta$, the firm could either face expected excess demand or excess supply respectively. Hence we define $\underline{\theta} \epsilon \Theta$ such that

$$
E_{\eta}\left[q^{d}\left(p^{s}\left(\frac{\theta}{c *}\right), \eta\right)\right] \geq f\left(n_{c *}^{\theta}\right)
$$

and $\bar{\theta} \otimes$ such that

$$
E_{\eta}\left[q^{d}\left(p^{s}\left(n_{c *}^{\bar{\theta}}\right), \eta\right)\right] \leq f\left(n_{c *}^{\bar{\theta}}\right) \text {. }
$$

$\left(n^{d}, p^{s}\right)$ vs. $\left(n^{d}, q^{s}\right)$ behavior:

(i) If random outcome $\theta$, then in $\left(n^{d}, p^{8}\right)$ behavior, the optimal solution is, by definition, $c \frac{\theta}{*}=\left(n_{c *}^{d}, n_{c *}^{\theta}\right)$, and maximum ex post $(\underline{\theta})$ expected profit, using $(5.1)$, is

$$
\pi_{c}\left(c \frac{\theta}{*}\right)=p^{s}\left(n_{c *}^{\theta}\right) \cdot f\left(\frac{\theta}{n^{*}}\right)+p^{s}\left(n_{c *}^{\frac{\theta}{*}}\right) \cdot v\left(n_{c *}^{\theta} p^{s}\left(n_{c *}^{\theta}\right)\right)-w^{s}\left(n_{c *}^{d}, \theta\right) \cdot n_{c *}^{\theta}
$$

In $\left(n^{d}, q^{s}\right)$ behavior, let a feasible solution $a-\theta=\left(n_{c *}^{d}, n_{c *}^{\theta}\right)$ be chosen. Substituting $a^{\theta}$ for $a_{*}^{\theta}$ in $(4.10)$, the ex post $(\underline{\theta})$ expected profit, after using $(4.3)$, is

$$
\pi_{a}(a \stackrel{\theta}{-})=E_{\eta}\left[p^{d}\left(f\left(n_{c *}^{\theta}\right), \eta\right)\right] \cdot f\left(n_{c *}^{\theta}\right)-w^{s}\left(n_{c *}^{d}, \underline{\theta}\right) \cdot n_{c *}^{\theta}
$$

Subtracting (5.5) from (5.6) yields 


$$
\begin{aligned}
& \pi_{a}\left(a^{\frac{\theta}{-}}\right)-\pi_{c}\left(c_{*}^{\frac{\theta}{*}}\right)=\left\{E_{\eta}\left[p^{d}\left(f\left(n_{c *}^{\theta}\right), \eta\right)\right]-p^{s}\left(n_{c *}^{\theta}\right)\right] \cdot f\left(n_{c *}^{\theta}\right) \\
& -p^{s}\left(n_{c *}^{\theta}\right) \cdot V\left(n_{c} \frac{\theta}{p}, p^{s}\left(\frac{\theta}{c *}\right)\right) \geq 0 \text {. }
\end{aligned}
$$

The above inequality holds because, firstly, $V(\cdot) \leq 0$, and secondly (5.3) and $F(4)$ imply $E_{\eta}\left[p^{d}\left(f\left(n \frac{\theta}{c *}\right), \eta\right)\right] \geq p^{s}\left(n \frac{\theta}{c *}\right)$.

(ii) If random outcome $\bar{\theta}_{2}$ then in $\left(n^{d}, p^{8}\right)$ behavior, the optimal solution is $c_{*}^{\bar{\theta}}=\left(n_{c *}^{d}, n_{c *}^{\bar{\theta}}\right)$ and the maximum ex post $(\bar{\theta})$ expected profit, using (5.2) is

$$
\begin{aligned}
\pi_{c}\left(c_{*}^{\bar{\theta}}\right)=p^{s}\left(n_{c *}^{\bar{\theta}}\right) \cdot E_{\eta}\left[q^{d}\left(p^{s}\left(n_{c *}^{\bar{\theta}}\right), \eta\right)\right] & +p^{s}\left(n_{c *}^{\bar{\theta}}\right) \cdot s\left(n_{c *}^{\bar{\theta}} p^{s}\left(n_{c *}^{\bar{\theta}}\right)\right) \\
& -w^{s}\left(n_{c *}^{d}, \bar{\theta}\right) \cdot n_{c *}^{\bar{\theta}} .
\end{aligned}
$$

In $\left(n^{d}, q^{s}\right)$ behavior, let a feasible solution; $a^{\bar{\theta}}=\left(n_{c *}^{d}, n_{a}^{\bar{\theta}}\right)$, be chosen. This is feasible because the ex ante $(\theta)$ variable, $n_{c *}^{d}$, is invariant to $\theta$. However, $\mathrm{n}_{\mathrm{a}}^{\bar{\theta}}$ satisfies

$$
f\left(n_{a}^{\bar{\theta}}\right)=E_{\eta}\left[q^{d}\left(p^{s}\left(n_{c *}^{\bar{\theta}}\right), \eta\right)\right]
$$

which from $F(4)$ implies

$$
E_{\eta}\left[p^{d}\left(f\left(n_{a}^{\bar{\theta}}\right), \eta\right]=p^{s}\left(n_{c *}^{\bar{\theta}}\right)\right.
$$

Whth this choice of $a^{\bar{\theta}}$, the ex post $(\bar{\theta})$ expected profit in $\left(n^{d}, q^{s}\right)$ behavior is

$$
\pi_{a}\left(a^{\bar{\theta}}\right)=E_{\eta}\left[p^{d}\left(f\left(n_{a}^{\bar{\theta}}\right), \eta\right)\right] \cdot f\left(n_{a}^{\bar{\theta}}\right)-w^{s}\left(n_{c *}^{d}, \bar{\theta}\right) \cdot n_{a}^{\bar{\theta}} \text {. }
$$

Subtracting (5.8) from (5.11), and using (5.9) and (5.10), yields

$$
\pi_{a}\left(a^{\bar{\theta}}\right)-\pi_{c}\left(c_{*}^{\bar{\theta}}\right)=-p^{s}\left(n_{c *}^{\bar{\theta}}\right) \cdot s\left(n_{c *}^{\bar{\theta}} p^{s}\left(n_{c *}^{\bar{\theta}}\right)\right)-w^{s}\left(n_{c *}^{d}, \bar{\theta}\right) \cdot\left[n_{c *}^{\bar{\theta}}-n_{a}^{\bar{\theta}}\right] \geq 0 .
$$

The above inequality holds because, firstly, $s\left({ }^{\circ}\right) \leq 0$ and secondly, (5.9) and (5.4) imply $f\left(n_{c *}^{\bar{\theta}}\right) \geq f\left(n_{a}^{\bar{\theta}}\right) \Rightarrow a_{c *}^{\bar{\theta}} \geq n_{a *}^{\bar{\theta}}$.

The inequalities (5.7) and (5.12) imply that for any state of nature $\theta$, $\pi_{a}\left(a^{\theta}\right) \geq \pi_{c}\left(c_{*}^{\theta}\right) \Rightarrow E\left[\pi_{a}\left(a^{\theta}\right)\right] \geq E\left[\pi_{c}\left(c_{*}^{\theta}\right)\right] \Rightarrow E\left[\pi_{a}\left(a_{*}^{\theta}\right)\right] \geq E\left[\pi_{c}\left(c_{*}^{\theta}\right)\right]$ since $a_{*}^{\theta}$ is by definition optimal in $\left(\mathrm{n}^{\mathrm{d}}, \mathrm{q}^{\mathrm{s}}\right)$ behavior. Q.E.D.

By analogously applying the above proof, the following result is easily established. 
Proposition 5.2. $\left(w^{d}, q^{8}\right)$ behavior is preferred to $\left(w^{d}, p^{8}\right)$ behavior.

Both Propositions 5.1 and 5.2 establish that the dominance of a quantity signal over a price signal in the output market. That the same holds true for input market signals is shown by the following results.

Proposition 5.3. $\quad\left(n^{d}, q^{s}\right)$ behavior is preferred to $\left(w^{d}, q^{8}\right)$ behavior.

Proof:

$\left(w^{d}, q^{s}\right)$ behavior: By definition, $b_{*}^{\theta}=\left(w_{b *}^{d}, n_{b *}^{\theta}\right)$ is optimal. The maximum expected profit, (4.14), is rewritten as

$$
E\left[\pi_{b}\left(b_{*}^{\theta}\right)\right]=E_{\theta}\left[R_{q}\left(n_{b *}^{\theta}\right)\right]-w_{b *}^{d} \cdot E_{\theta}\left[n_{b *}^{\theta}\right] .
$$

Note that because of inequality in (4.13),

$$
E_{\theta}\left[n_{b *}^{\theta}\right] \leq E_{\theta}\left[n^{s}\left(w_{b *}^{d}, \theta\right)\right]
$$

$\left(w^{d}, q^{s}\right)$ vs. $\left(n^{d}, q^{s}\right)$ behavior :

In $\left(n^{d}, q^{s}\right)$ behavior, let a feasible solution, $a=\left(n_{a}^{d}, n_{a}^{d}\right)$, be chosen such that

$$
n_{a}^{d}=E_{\theta}\left[n_{b *}^{\theta}\right]
$$

Substituting solution, $a$, for $a_{*}^{\theta}$ in $(4.10)$, the expected profit is

$$
E\left[\pi_{a}(a)\right]=E_{\theta}\left[R_{q}\left(n_{a}^{d}\right)-w^{8}\left(n_{a}^{d}, \theta\right) \cdot n_{a}^{d}\right] \text {. }
$$

Subtracting (5.13) from (5.16), and then using (5.15), yields

$$
\begin{aligned}
E\left[\pi_{a}(a)\right]-E\left[\pi_{b}\left(b_{*}^{\theta}\right)\right] & =\left\{R_{q}\left(E_{\theta}\left[n_{b *}^{\theta}\right]\right)-E_{\theta}\left[R_{q}\left(n_{b *}^{\theta}\right)\right]\right\} \\
& +\left\{w_{b *}^{d}-E_{\theta}\left[w^{s}\left[E_{\theta}\left[n_{b *}^{\theta}, \theta\right]\right\} \cdot E_{\theta}\left[n_{b *}^{\theta}\right] \geq 0 .\right.\right.
\end{aligned}
$$

The above inequality holds because firstly, $R_{q}(\cdot)$ is concave and therefore by Jensen's inequality, $R_{q}\left(E_{\theta}\left[n_{b *}^{\theta}\right]\right) \geq E_{\theta}\left[R_{q}\left(n_{b *}^{\theta}\right)\right]$, and second $1 y$, (5.14) and $F(8)$ imply $w_{b *}^{d} \geq E_{\theta}\left[w^{8}\left(E_{\theta}\left[n_{b *}^{\theta}\right], \theta\right)\right]$. Q.E.D.

By analogously applying the above proof, but this time using the assumption that $R_{p}(\cdot)$ is concave, the following result is easily established. 
Proposition 5.4. $\left(n^{d}, p^{8}\right)$ behavior is preferred to $\left(w^{d}, p^{8}\right)$ behavior.

Finally, both Propositions 5.1 and 5.4 or Propositions 5.2 and 5.3

Imply

Proposition 5.5. $\quad\left(n^{d}, q^{s}\right)$ behavior is preferred to $\left(w^{d}, p^{8}\right)$ behavior.

Quantity signals in the $(I, 0)$ behavioral class, therefore, generally

dominate price signals. This occurs for two separate reasons as can be inferred from the proofs. Firstly, the concavity of the expected revenue product functions defined in the input quantity space, $R_{q}(\cdot)$ and $R_{p}(\cdot)$, imply, by Jensen's inequality, that expected revenue (and hence expected profit) is lower, ceteris paribus, the greater the uncertainty. in quantities of input supply.

Thus, the input quantity signal dominates the input price signal since the latter, but not the former, elicits uncertain quantity responses of input supply. Secondly, in the $(I, 0)$ behavior, the output is already produced before sales are conducted. Thus, the use of quantity as a sales signal (which results in the expected revenue product function defined by $R_{q}(\cdot)$ ) dominates the use of a price signal (in which case $R_{p}(\cdot)$ is the expected revenue product function) simply because $R_{p}(\cdot)$, but not $R_{q}(\cdot)$, contains the element of possible 1088 due to unsold inventorles whenever demand falls short of production.

5.2 Relative Dominance of Experiments Withth the Class of $(0, I)$ Behavior. In the $(0, I)$ behavioral class, the feasible experiments as shown in Table II are reduced to the $\left(q^{8}, n^{d}\right)$ and $\left(p^{8}, n^{d}\right)$ experiments. It is shown below that the relative dominance between them depends critically on whether the expected marginal cost is an increasing or decreasing function of output. 
Proposition 5.6. For increasing (decreasing) expected marginal cost firms, $\left(q^{s}, n^{d}\right)$ behavior is preferred (dispreferred) to $\left(p^{s}, n^{d}\right)$ behavior.

Proof:

(i) The case of increasing expected marginal cost: In $\left(p^{8}, n^{d}\right)$ behavior, $c_{*}^{\eta}=\left(p_{c *}^{8}, q_{c *}^{\eta}\right) 18$, by definition, optimal and the maximum expected profit is as in (4.43). In $\left(q^{8}, n^{d}\right)$ behavior, let a feasible solution, a a $\left(q_{a}^{8}, q_{a}^{8}\right)$, be chosen such that

$$
q_{a}^{8}=E_{\eta}\left[q_{c *}^{\eta}\right]
$$

Substituting solution, $a$, for $a_{*}^{\eta}$ in (4.39),

$$
E[a(a)]=E_{\eta}\left[p^{d}\left(q_{a}^{s}, \eta\right)\right] \cdot q_{a}^{s}-c\left(q_{a}^{s}\right) .
$$

Subtracting (4.43) from (5.19), and using (5.18), yields

$$
\begin{aligned}
E\left[{ }_{a} \pi(a)\right]-E\left[c_{c} \pi\left(c_{*}^{\eta}\right)\right] & =\left\{E_{\eta}\left[p^{d}\left(E_{\eta}\left[q_{c *}^{\eta}\right], \eta\right)\right]-p_{c *}^{s}\right\} \cdot E_{\eta}\left[q_{c *}^{\eta}\right] \\
& +\left\{E_{\eta}\left[c\left(q_{c *}^{\eta}\right)\right]-c\left(E_{\eta}\left[q_{c *}^{\eta}\right]\right)\right]>0
\end{aligned}
$$

The above inequality holds because firstly, the inequality in (4.42) implies $E_{\eta}\left[q_{c *}^{\eta}\right] \leq E_{\eta}\left[q^{d}\left(p_{c *}^{s}, \eta\right)\right]$ which together with $F(4)$ imply $E_{\eta}\left[p^{d}\left(E_{\eta}\left[q_{c *}^{\eta}\right], \eta\right)\right] \geq p_{c *}^{8}$; and secondly, $c^{\prime \prime}>0$ and by Jensen's inequality, $E_{\eta}\left[c\left(q_{c *}^{\eta}\right)\right]>c\left(E_{\eta}\left[q_{c *}^{\eta}\right]\right)$.

(ii) The case of decreasing expected marginal cost: In this case, $c^{\prime \prime}<0$ and hence the optimal solution in $\left(q^{s}, n^{d}\right)$ behavior, $a_{*}^{\eta} \equiv\left(q_{a *}^{8}, q_{a *}^{\eta}=q_{a *}^{8}\right)$ since it is clear that optimal sales $q_{a *}^{\eta}=q_{a *}^{s}$ because the firm would exploit its decreasing expected marginal cost condition by making a maximum permissible sales contract. Using $a_{*}^{\eta}=\left(q_{a *}^{8}, q_{a *}^{8}\right)$, the maximum expected profit in (4.39) is modified to

$$
E\left[a \pi\left(a_{*}^{\eta}\right)\right] \equiv E_{\eta}\left[p^{d}\left(q_{a *}^{s}, \eta\right)\right] \cdot q_{a *}^{s}-C\left(q_{a *}^{s}\right) .
$$

In $\left(p^{s}, n^{d}\right)$ behavior, let a feasible solution, $c^{\eta}=\left(p_{c}^{s}, q^{d}\left(p_{c}^{s}, \eta\right)\right)$, be chosen such that 


$$
p_{c}^{s}=E_{\eta}\left[p^{d}\left(q_{a *}^{8}, \eta\right)\right]
$$

which from $F(4)$ implies

$$
E_{\eta}\left[q^{d}\left(p_{c}^{s}, \eta\right)\right]=q_{a *}^{s}
$$

Substituting $c^{\eta}$ for $c_{*}^{\eta}$ in (4.43),

$$
E\left[c_{c} \pi\left(c^{\eta}\right)\right]=p_{c}^{s} \cdot E_{\eta}\left[q^{d}\left(p_{c}^{s}, \eta\right)\right]-E_{\eta}\left[C\left(q^{d}\left(p_{c}^{s}, \eta\right)\right)\right]
$$

Subtracting (5.20) from (5.23), and using (5.21) and (5.22), yields

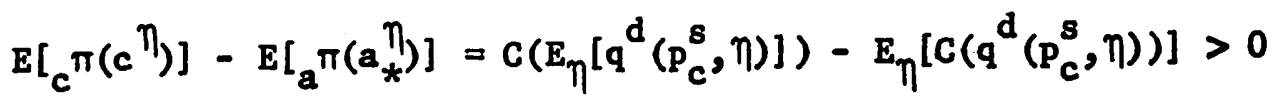

owing to Jensen's inequality because $c^{\prime \prime}<0$.

Q.E.D.

The above results are now explained. If the expected cost function 1s convex, then Increasing uncertainty in output demand, by Jensen's inequality, would, ceteris paribus, Increase the expected cost and hence decrease the expected profit. Conversely, increasing output demand uncertainty would, ceteris paribus, increase the expected profit level if the expected cost function is concave. Thus, in the case of increasing expected marginal cost (or convex expected cost function), a quantity signal dominates a price signal since the latter, but not the former, elicits uncertain responses in quantity demand. The converse reasoning easily establishes the dominance of the price over the quantity signal if the expected marginal cost is decreasing.

5.3 Relative Dominance of Experiments Within the Class of $\left(\begin{array}{l}I \\ 0\end{array}\right)$ Behavior.

The relative dominance between experiments in the $\left(\begin{array}{l}I \\ 0\end{array}\right)$ behavioral class is easily established in light of earlier results. Observe that in the $(I, 0)$ behavioral class, the input quantity dominates the input price signal when the expected revenue product functions are concave. Also note that in the $(0, I)$ behavioral class, the output quantity dominates the output price signal whenever the expected cost function is convex. Now, in the $\left(\begin{array}{l}I \\ 0\end{array}\right)$ behavioral class, if the production function, $f(\cdot)$, is concave, this is easily translated, given 
the linear approximations of the Input supply and output demand functions, Into e1ther a concave expected revenue product function or a convex expected cost function. Thus, if $f(\cdot)$ is concave, it is easily verifled that quantity would dominate price signals in both the input and output markets. This is stated as Proposition 5.7. If $f(\cdot)$ is a concave function, then $\left(\frac{n^{d}}{q}\right)$ behavior 1s preferred to either $\left(w_{s}^{d}\right)$ or $\left(\sum_{p}^{n}\right)$ behavior which in turn is preferred to $\left.\mathrm{p}^{\mathrm{d}} \mathrm{s}\right)$ behavior.

6. RELATIVE DOMINANCE OF ACROSS CLASS EXPERIMENTS

In this section we turn to examine the relative dominance between experiments belonging to different classes of behavior. In particular, we consider the two following distinct issues.

Firstly, since the comparison of experiments belonging to different behavioral classes involves experiments which may differ in their input and output signal combinations, it is desirable to isolate from the effects of price versus quantity decisions which have been extensively studied in the preceding section and focus on experiments with a similar input and output signal combination. For instance, the experiments, $\left(n^{d}, q^{s}\right) \in(I, 0),\left(q^{s}, n^{d}\right) \in(0, I)$, and $\left(\begin{array}{l}n \\ q\end{array}\right) \in\left(\begin{array}{l}I \\ 0\end{array}\right)$, have a similar input and output signal combination but they belong to different behavioral classes. Abstracting from the effects of price versus quantity decisions, the conditions governing the preference of one behavioral class over another is best illustrated by considering the following two diametrically extreme situations. Defining $O_{u}$ as a situation where uncertainty exists in the output demand but not in the input supply condition and $I_{u}$ as a situation in reverse, then $i t$ is readily verified ${ }^{9}$ that $\frac{\text { Proposition } 6.1}{d} \quad$ Under $I_{u}\left(0,2,\left(n, a^{d}\right) a(I, 0)\right.$ behavior is preferred (dispreferred) to $\left(\begin{array}{l}n \\ q\end{array}\right) \in\left({ }_{0}^{I}\right)$ behavior, which in turn is preferred (dispreferred) to $\left(q^{s}, n^{d}\right) \in(0, I)$ behavior. 
This result is obvious from the following 1llustration. Consider the ordered cholce vectors: $(I, \theta, n, q, 0, \eta) \in(I, 0)$ behavior; $(I, 0, \theta, \eta, n, q)$ e $\left(\begin{array}{l}I \\ 0\end{array}\right)$ behavior; and $(0, \eta, q, n, I, \theta) \in(0, I)$ behavior. Without output market uncertainty, the variable $\eta$ can be deleted as irrelevant and the above decision vectors reduce to $(I, \theta, n, q, 0)$ \& $(I, 0)$ behavior; $(I, 0, \theta, n, q) \in\left(I_{0}^{I}\right)$ behavior; and $(0, q, n, I, \theta) \in(0, I)$ behavior. Now. comparing the number of decision variables that have to be made ex ante $(\theta)$ and ex post $(\theta)$ between the behavioral classes clearly reveals the $(I, 0)$ behavior 1s more informative than $\left(\begin{array}{l}I \\ 0\end{array}\right)$ behavior which in turn is more informative than $(0, I)$ behavior. Thus, in this polar example where uncertainty exists only in the input market, Blackwell's.principle of greater informativeness clearly establishes $\left(n^{d}, q^{8}\right)$ to be preferred to $\left(\mathrm{n}^{8}\right)$ which in turn is preferred to $\left(q^{8}, n^{d}\right)$ behavior. In the opposite polar case where uncertainty exists only in output market, a simflar reasoning would verify that the dominance is in the reverse direction. In other words, if uncertainty only exists in the input supply but not the output demand condition, then it 18 optimal to use an $\left(n^{d}, q^{8}\right)$ strategy to experiment first in the input market and resolve any further uncertainty in this market by making an input purchase contract. This strategy leaves the firm with no uncertainty at all when it makes its output sales. In contrast, the $\left(q^{8}, n^{d}\right)$ strategy, which involves experimenting first in the output market, is inferior since the absence of uncertainty in the output market makes any experiment redundant and not only so, the firm has to bear the full brunt of the input market uncertainty when it makes its input purchase to satisfy a prior sales contract. If, however, uncertainty exists in the output, but not the input market, the converse of the.above argument easily establishes the optimality of the $\left(q^{3}, n^{d}\right)$ strategy. From this, we conjecture that if uncertainty were to exist in both markets, then the $\left(n^{d}, q^{8}\right)$ strategy 
18 most preferred if uncertainty in the input market is large relative to that In the output market whereas the $\left(q^{*}, n^{d}\right)$ strategy is most preferred if the converse is true.

It is Important to emphasize that Proposition 6.1 may not be generalized to the group of behavior: $\left(n^{d}, p^{8}\right) \in(I, 0),\left(\frac{n^{d}}{p^{8}}\right) \in\left(\begin{array}{l}I \\ 0\end{array}\right)$, and $\left(p^{8}, n^{d}\right),(0, I)$. For instance, under $o_{u}$ (uncertainty existing only in the output market), It 1s generally not true that $\left(p^{8}, n^{d}\right)$ is the most preferred and $\left(n^{d}, p^{8}\right)$ is the least preferred behavior. Proposition 6.4 below, which is trivially applicable under $o_{u}$, shows that $\left(n^{d}, p^{s}\right)$ may, under some circumstances, dominate $\left(p^{8}, n^{d}\right)$ behavior. The above anomaly arlses because the profit functions $\pi_{\mathrm{a}}(\cdot), \pi_{A}(\cdot)$ and $a^{\pi(\cdot)}$ corresponding to the group of behavior: $\left(n^{d}, q^{8}\right),\left(\frac{n^{d}}{q^{8}}\right)$ and $\left(q^{8}, n^{d}\right)$, are Identical whereas the profit functions $\pi_{c}(\cdot), \pi_{c}(\cdot)$ and ${ }_{c}(\cdot)$ corresponding the group of behavior: $\left(n^{d}, p^{s}\right),\left(p^{8}\right)$ and $\left(p^{s}, n^{d}\right)$, In general, differ. In particular, recall that implicit in the $\pi_{c}(\cdot)$ function is an element of loss due to unsold Inventory which 18 absent in elther $\pi_{c}(\cdot)$ or $\pi_{c}(\cdot)$. Hence Blackwell's criterion may not be generally applicable to establiah dominance among the latter group of behavior. 10

Secondly, the two issues if price versus quantity decisions and the decisions on which market to experiment first are now considered simultaneously. Essentially, it involves the examination of behavioral dominance between experiments which not only belong to different behavior classes but which also differ in their Input and output signal combinations. The focus is on three experiments, $\left(n^{d}, q^{8}\right) \in(I, 0),\left(p^{s}, n^{d}\right) \in(0, I)$, and $\left(n^{d}, p^{8}\right) \in(I, 0)$, which are analogous to the quantity-setting, price-setting, and quantity-cum-price setting behavior discussed in earlier literature by Baron [2], Leland [4] and Lim [6]. Why this literature has restricted the feasible behavioral set to the above three modes is a direct consequence of the fact the input market and its uncertainty have been ignored. The analogy 
between the above two sets. of behavior becomes apparent when we consider the following 1llustration. Recall the $\left(n^{d}, q^{8}\right) \in(I, 0)$ behavior with Its choice vector $\left(n^{d}, \theta, n, q, q^{8}, \eta\right)$; the $\left(p^{8}, n^{d}\right) \in(I, 0)$ behavior with 1ts choice vector $\left(p^{8}, \eta, q, n, n^{d}, \theta\right)$; and the $\left(n^{d}, p^{8}\right) \in(I, 0)$ behavior with 1ts choice vector $\left(n^{d}, \theta, n, q, p^{8}, \eta\right)$. Now if we ignore the input market and its uncertainty, the Input market variables $n^{d}, n$, and $\theta$ become irrelevant. Furthermore, if we focus only on the ex ante $(\eta)$ varlables the above choice vectors are reduced to the following: the cholce vector $\left(q^{8}, \eta\right)$ for the $\left(n^{d}, q^{8}\right) \&(I, 0)$ behavior (note that optimality requires $q=q^{8}$, hence $q$ can be dropped), the choice vector $\left(p^{8}, \eta\right)$ for the $\left(p^{8}, n^{d}\right) \in(0, I)$ behavior, and the cholce vector $\left(q, p^{8}, \eta\right)$ for the $\left(n^{d}, p^{8}\right)$ e $(I, 0)$ behavior. Based on the ex ante $(\eta)$ choice variables, they are appropriately termed in the literature as the quantity-setting, price-setting, and quantity-cum-price setting behavior respectively. Lim's [6] results on the behavioral dominance among these three modes are now generalized to Include Input market uncertainty.

Proposition 5.2 For increasing expected marginal cost, $\left(n^{d}, q^{s}\right) \in(I, 0)$ is preferred to $\left(p^{s}, n^{d}\right) \in(0, I)$ behavior.

Proof: In $\left(p^{s}, n^{d}\right)$ behavior, $c_{*}^{\eta} \equiv\left(p_{c^{*}}^{s}, q_{c^{*}}^{\eta}\right)$ is, by definition, optimal and the maximum expected profit is as in (4.43), and rewritten as

$$
E\left[c^{\pi}\left(c_{*}^{\eta}\right)\right] \equiv p_{c^{*}}^{s} E_{\eta}\left[q_{c^{*}}^{\eta}\right]-E_{\eta}\left[C\left(q_{c *}^{\eta}\right)\right]
$$

In $\left(n^{d}, q^{s}\right)$ behavior, let a feasible situation, $a=\left(n_{a}^{d}, n_{a}^{d}\right)$, be chosen such that $f\left(n_{a}^{d}\right)=E_{\eta}\left[q_{c^{*}}^{\eta}\right]$. Now, since $E_{\eta}\left[q_{c^{*}}^{\eta}\right] \leq E_{\eta}\left[q^{d}\left(p_{c^{*}}^{s}, \eta\right)\right]$ and because of $F(4)$, we have

$$
E_{n}\left[p^{d}\left(f\left(n_{a}^{d}\right), \eta\right)\right] \geq p_{c^{*}}^{s}
$$


The expected profit in $\left(n^{d}, q^{s}\right)$ behavior from the choice of solution, $a$,

$$
E\left[\pi_{a}(a)\right]=E_{\eta}\left[p^{d}\left(f\left(n_{a}^{d}\right), p\right)\right] f\left(n_{a}^{d}\right)-E_{\theta}\left[w^{s}\left(n_{a}^{d}, \theta\right)\right] \cdot n_{a}^{d} .
$$

Subtracting (6.1) from (6.3), and noting that $n_{a}^{d}=h\left(E_{\eta}\left[q_{c^{*}}^{\eta}\right]\right)$ and the definition of $\mathrm{C}($.$) in (4.33)$,

$$
\begin{aligned}
E\left[\pi_{a}(a)\right]-E\left[c^{\pi}\left(c_{*}^{\eta}\right)\right] & =\left\{E_{\eta}\left[p^{d}\left(f\left(n_{a}^{d}\right), \eta\right)\right]-p_{c^{*}}^{s}\right\} f\left(n_{a}^{d}\right) \\
& +\left\{E_{\eta}\left[C\left(q_{c^{*}}^{\eta}\right)\right]-c\left(E_{\eta}\left[q_{c^{*}}^{\eta}\right]\right)\right\}>0 .
\end{aligned}
$$

The above inequality is due to $(6.2)$ and Jensen's inequality since $C($.$) is$ strictly convex. Q.E.D.

Proposition 6.3 For increasing expected marginal cost, $\left(n^{d}, q^{s}\right) \in(I, 0)$ is preferred to $\left(n^{d}, p^{s}\right) \in(I, 0)$ behavior.

The above follows from proposition 5.1 which holds irrespective of whether expected marginal cost is increasing or decreasing.

Proposition 6.4 For increasing expected marginal cost, $\left(p^{s}, n^{d}\right) \varepsilon(0, I)$ is not always preferred to $\left(n^{d}, p^{s}\right) \in(I, 0)$ behavior.

Proof: In $\left(p^{s}, n^{d}\right)$ behavior, $c_{*}^{\eta} \equiv\left(p_{c^{*}}^{s}, q_{c^{*}}^{\eta}\right)$ is, by definition, optimal and the maximum expected profit is $(6.1)$. In $\left(n^{d}, p^{s}\right)$ behavior, $c_{*}^{\theta}=\left(n_{c^{*}}^{d}, n_{c^{*}}^{\theta}, p^{s}\left(n_{c^{*}}^{\theta}\right)\right)$ is, by definition, optimal. Nevertheless, let an arbitrary feasible solution, $c=\left(n_{c}^{d}, n_{c}^{d}, p_{c *}^{s}\right)$, be chosen such that

$$
f\left(n_{c}^{d}\right)=E_{\eta}\left[q_{c^{*}}^{\eta}\right] \Rightarrow n_{c}^{d}=h\left(E_{\eta}\left[q_{c^{*}}^{\eta}\right]\right) \text {. }
$$

Substituting $c$ for $c_{*}^{\theta}$ in $(4.27)$ and using (4.16), the expected profit from the choice of solution $c$,

$$
E\left[\pi_{c}(c)\right]=p_{c^{*}}^{s}\left\{f\left(n_{c}^{d}\right)+V\left(n_{c^{d}}^{d}, p_{c^{*}}^{s}\right)\right\}-E_{\theta}\left[w^{s}\left(n_{c^{d}}^{d}, \theta\right)\right] n_{c^{-}}^{d}
$$


Subtracting (6.1) from (6.5) yields, after using (6.4) and noting the definition of $C($.$) in (4.33)$,

$$
E\left[\pi_{c}(c)\right]-E\left[{ }_{c} \pi\left(c_{*}^{\eta}\right)\right]=p_{c *}^{s} V\left(n_{c^{\prime}} p_{c^{*}}\right)+\left\{E_{\eta}\left[C\left(q_{c^{*}}^{\eta}\right)\right]-C\left(E_{\eta}\left[q_{c^{*}}^{\eta}\right]\right)\right\} \text { (6.6) }
$$

which cannot be unambiguously signed since in the R.H.S. of (6.6), the first. term is non-positive and the second term is positive by Jensen's inequality since $C($.$) is strictly convex. Since \nabla($.$) strictly depends on the nature of$ the demand condition which is totally unrelated to the cost condition, there exists some demand and cost conditions whereby $(6.6)$ is non-negative. In an example considered by $\operatorname{Lim}[6]$ involving a quadratic cost function and a linear demand function, it was shown that for any given variance in demand, (6.6) tends to be positive the larger the slope of the marginal cost function. Q.E.D. The ambiguity in the dominance relationship between $\left(n^{d}, p^{8}\right)$ and $\left(p^{8}, n^{d}\right)$ experiments is due to the following. First, $\left(n^{d}, q^{s}\right)$ dominates $\left(n^{d}, p^{s}\right)$ behavior for the reason provided earlier which is essentially the disadvantage of the latter in having to absorb a possible loss due to unsold inventories. Second, and for a separate reason, $\left(n^{d}, q^{s}\right)$ dominates $\left(p^{8}, n^{d}\right)$ behavior because the latter, but not the former, strategy elicits random quantity responses in output demand which puts it at a disadvantage in light of the convexity of the expected cost function. Thus, the dominance between $\left(n^{d}, p^{s}\right)$ and $\left(p^{s}, n^{d}\right)$ behavior is ambiguous depending on the sizes of the above two off-setting disadvantages. Proposition 6.4 trivially applies under $0_{u}$ (uncertainty existing only in the output market). Thus under $0_{u^{\prime}}\left(p^{8}, n^{d}\right)$ does not generally dominate $\left(n^{d}, p^{8}\right)$; hence $1 t$ conflms our previous claim that Proposition 6.1 does not generalize to the group of behavior: $\left(n^{d}, p^{8}\right),\left(p^{8}\right)$ and $\left(p^{B}, n^{d}\right)$. 
For decreasing expected marginal cost, due to the difficulty of establishing general results, we shall nevertheless consider the cases where the input purchase contract for the $\left(n^{d}, q^{s}\right)$ behavior is bound by the input signal, i.e., $n=n^{d}$, and the sales contract for the $\left(p^{s}, n^{d}\right)$ behavior is bound by the response to the output signal, i.e., $q=q^{d}\left(p^{8}, \eta\right)$. For these plausible cases, we have

Proposition 6.5 For decreasing expected marginal cost, $\left(p^{8}, n^{d}\right) \in(I, 0)$, is preferred to $\left(n^{d}, q^{s}\right) \in(I, 0)$ which in turn is preferred to $\left(n^{d}, p^{s}\right) \in(I, 0)$ behavior.

Proof: In $\left(n^{d}, q^{8}\right)$ behavior, $a_{*}^{\theta} \equiv\left(n_{a^{*}}^{d}, n_{a^{*}}^{\theta}\right)$, is by definition, optimal. If the input purchase is constrained to be equal to the input signal, then $n_{a *}^{\theta}=n_{a *}^{d}$ and the maximum expected profit in $(4.10)$ can be rewritten as

$$
E\left[\pi_{a}\left(a_{*}^{\theta}\right)\right]=E_{\eta}\left[p^{d}\left(f\left(n_{a^{*}}^{d}\right), \eta\right)\right] f\left(n_{a^{*}}^{d}\right)-E_{\theta}\left[w^{s}\left(n_{a^{*}}^{d}, \theta\right)\right] n_{a^{*}}^{d}
$$

In $\left(p^{s}, n^{d}\right)$ behavior, let a feasible solution, $c^{\eta} \equiv\left(p_{c}^{s}, q^{d}\left(p_{c}^{s}, \eta\right)\right)$, be chosen such that

$$
p_{c}^{s}=E_{\eta}\left[p^{d}\left(f\left(n_{a^{*}}^{d}\right), \eta\right)\right]
$$

which from $F(4)$ implies

$$
E_{\eta}\left[q^{d}\left(p_{c}^{s}, \eta\right)\right]=f\left(n_{a^{*}}^{d}\right) \Rightarrow n_{a^{*}}^{d}=h\left(E_{\eta}\left[q^{d}\left(p_{c}^{s}, \eta\right)\right]\right) \text {. }
$$

The expected profit in $\left(p^{s}, n^{d}\right)$ behavior from the choice of solution $c^{\eta}$,

$$
E\left[c^{\pi}\left(c^{\eta}\right)\right]=p_{c}^{s} E_{\eta}\left[q^{d}\left(p_{c}^{s}, \eta\right)\right]-E_{\eta}\left[C\left(q^{d}\left(p_{c}^{s}, \eta\right)\right)\right]
$$

Subtracting (6.7) from (6.10) yields, after noting (6.8), (6.9) and the definition of $\mathrm{C}($.$) in (4.33),$

$$
E\left[c \pi\left(c^{\eta}\right)\right]-E\left[\pi_{a}\left(a_{*}^{\theta}\right)\right]=C\left(E_{\eta}\left[q^{d}\left(p_{c}^{s}, \eta\right)\right]\right)-E_{\eta}\left[C\left(q^{d}\left(p_{c}^{s}, \eta\right)\right)\right]>0
$$


because of Jensen's inequality since $C($.$) is strictiy concave. Thus for de-$ creasing expected marginal cost, $\left(p^{s}, n^{d}\right)$ is preferred to $\left(n^{d}, q^{s}\right)$ behavior which in turn is preferred to $\left(\mathrm{n}^{\mathrm{d}}, \mathrm{p}^{\mathrm{s}}\right)$, behavior by proposition 5.1. Q.E.D. For decreasing expected marginal cost, we find $\left(p^{s}, n^{d}\right)$ to dominate $\left(n^{d}, q^{s}\right)$ behavior. The reason is due to the concavity of the expected cost function, which by Jensen's inequality, implies that, ceteris paribus, expected cost decreases with uncertain quantity demand. Thus, the $\left(p^{s}, n^{d}\right)$ dominates the $\left(n^{d}, q^{s}\right)$ strategy since the former, but not the latter, elicits random quantity responses in demand. Furthermore, $\left(n^{d}, q^{s}\right)$ in turn dominates $\left(n^{d}, p^{s}\right)$ behavior for the reason provided earlier.

\section{CONCLUDING REMARRS}

In summary, we have shown how a firm facing both Input supply and output demand uncertainty may adopt varlous strategles differentlated according to the timing of experimentation, using price or quantity signals, between the input and output markets. A behavior or experiment, therefore, could differ from another depending on (a) whether price of quantity signals are used in the experiment in each market, and on (b) whether it belongs to the $(I, 0)$ strategy (where the input signalling precedes the output signalling experiment), or the $(0, I)$ strategy (where the output signalling precedes the Input signaliing experiment) or the $\left(\frac{I}{0}\right)$ strategy (where both the input and output signalling experiments are conducted simultaneously). All these experiments seem to be equally Informative á la Blackwe11 and hence the dominance relationship among them cannot appeal simply to the criterion of information superiority. Instead the relative dominance of experiments within and across the behavioral classes is due to the following issues. 
On the first issue of price versus quantity decisions, it is certainly not apparent whether or not price should dominate quantity signals. The reason is that in a price signalling experiment, the firm has to absorb uncertainty in quantity responses, but so must it absorb uncertainty of price responses in a quantity signalling experiment. We have, however, been able to obtain some striking results which are the following.

On the one hand, we found quantity to dominate price signals in both the input and output markets whenever the following conditions occur: diminishing expected marginal revenue product (or concave expected revenue product functions) in the $(I, 0)$ strategy; increasing expected marginal cost (or convex expected cost functions) in the $(0, I)$ strategy; and diminishing marginal product (or concave production functions which incidentally can be translated into either a concave expected revenue product function or a convex expected cost function) in the $\left(\begin{array}{l}I \\ 0\end{array}\right)$ strategy. To explain these results, observe that the concavity of the expected revenue product function (defined on the input quantity space) and the convexity of the expected cost function (defined on the output quantity space) imply, by Jensen's inequality, that expected profit would be smaller, ceteris paribus, the greater the uncertainty in quantities of input supply and of output demand respectively. For this reason and also the fact that prices, but not quantity signals, elicit uncertain quantity responses in input supply or output demand, it follows that in the $(I, 0)$ strategy, the input quantity dominates the input price signals; in the $(0, I)$ strategy, the output quantity dominates the output price signal; and in the $\left(\begin{array}{l}I \\ 0\end{array}\right)$ strategy, both input and output quantity signals dominate the price signals. What remains to be explained is the dominance of the quantity over the price signal in the output market in the $(I, 0)$ strategy. This result is attributed to the fact that in the $(I, 0)$ 
strategy, sales are conducted after the output is produced. Hence, using an output price signal, as opposed to a quantity signal, in the conduct of sales is disadvantageous since it may incur a loss.due to unsold inventories whenever output demand falls below the production level.

The only situation where the price signal dominates the quantity signal is in the $(0, I)$ strategy whenever the expected marginal cost is a decreasing function of output (or concave expected cost function). To explain this result, again observe that the concavity of the expected cost function Implies, by Jensen's inequality, that expected cost is smaller (and hence the expected profit is greater), ceteris paribus, the greater the uncertainty In quantities of output demand. Thus, because the price, but not the quantity, signal elicits uncertain quantity responses in output demand, it follows that the output price signal is superior.

Thus, except for the singular case of decreasing expected marginal cost in the $(0, I)$ behavioral class, quantity generally dominates price signals under most plausible conditions. This is a striking result which have important implications. In a world without an omniscient auctioneer who freely supplies information on trading prices, price setting by the firm is a very natural way in the conduct of trade. Its dominance by strategies involving quantity signals is indeed surprising. To rationalize this, observe that a quantity signalling experiment presumes that for any offer of a quantity for sale or purchase, there exists some response price at which no more than whatever quantity is offered by the firm is bought or sold. The natural question, then is how such a response is being determined. This question is not explicitly considered in our model in which a price response to a quantity signal is treated symmetrically as an exogenous variable just as is a quantity response to a price signal. However, it is clear that the feasibility of a 
quantity signalling experiment may have to depend on the existence of intermediate trading agents that would respond with a trading price to the firm's quantity offer. Interpreted in this manner, the very domination of a quantity over a price signalling experiment suggests that firms should be willing, in order to operate a quantity signalling experiment, to offer premiums to intermediate trading agents rather than having to use price signals to conduct output sales (retailifig) or input purchase where it directly assumes the risk of unsold inventory or under-employment of input respectively. This risk is effectively shifted to intermediate trading agents in a quantity signalling experiment. The existence of private employment agencies, and retallers are some examples of the intermediate trading agents discussed above. Their existence is otherwise difficult to rationalize in a model without uncertainty since the firm could very well have undertaken all the input purchase and output selling activities by Itself.

The second issue we addressed was the relative dominance between experiments that belong to different behavioral classes differentiated according to the sequence of experimentation between the input and output markets. On this matter, and abstracting from the issue of price versus quantity declsions, we found that the $\left(n^{d}, q^{3}\right) \in(I, 0)$ strategy to be most preferred if the input market uncertainty is large relative to the output market uncertainty, but the $\left(q^{8}, n^{d}\right)$ e. $(0, I)$ strategy is most preferred if the converse is true. Thls fairly obvious result is explained below. In $\left(n^{d}, q^{8}\right) \in(I, 0)$ or 'buy-then-Bell' strategy, the firm experiments first in the input market and any further uncertainty in this market does not exist after it makes 1ts Input purchase contract. However, its output sales must bear the remaining uncertainty in the output market. In contrast, the $\left(q^{8}, n^{d}\right) \in(0, I)$ or 'sell-then-buy' strategy, the initial experiment in the output market resolves 
any further uncertainty in this market after its output sales contract mast: bear the brunt of the Input market uncertainty. Hence, everything else constant, a strategy that experiments first in the market with a larger degree of uncertainty is generally preferred to one which experiments in it last because the former (as opposed to the latter) strategy would leave a smaller amount of uncertainty to be borne in the remaining market. Finalay, the senerallzeci versiuns (tu inclucie the input mariket uncertainty) of the three behavioral modes considered by Baron [2], Leland [4] and Lim [6] are but a small subset of the possible behavioral modes considered in this model. In the framework of this model, these behavioral modes not only belong to different behavioral classes but they differ also In the use of price and quantity signals. The evaluation of their relative dominance essentially generalizes LIm's [6] results. 
${ }^{1}$ This is equivalent to proving $q_{c} \leqq q^{d}\left(p_{c}, \eta^{0}\right) \theta_{c} p_{c} p^{d}\left(q_{c}, \eta^{0}\right)$ Proof: (a) If $q_{c} \leq q^{d}\left(p_{c}, \eta^{\circ}\right)$, then, because $q_{1}<0$, there must exist a non-negative constant $6 \geq 0$, such that $q^{c}=q^{d}\left(p_{c}+c, \eta^{\circ}\right)$. Since this function is invertible, we can write $p_{c}+\epsilon=p^{d}\left(q_{c}, \eta^{0}\right) \Rightarrow p_{c} \leq p^{d}\left(q_{c}, \eta^{\circ}\right)$. The converse is true by a similar proof since $p_{1}<0$.

(b) If $q_{c}>q^{d}\left(p_{c}, \eta^{0}\right)$, then $q_{1}<0$ implies there exists a positive constant, $\delta>0$, such that $q_{c}=q^{d}\left(p_{c}-\delta, \eta^{0}\right)$. Since this function is invertible, we can write $p_{c}-\delta=p^{d}\left(q_{c}, \eta^{0}\right) \Rightarrow p_{c}>p^{d}\left(q_{c}, \eta^{0}\right)$. The converse is true by a similar proof since $p_{1}<0$. Q.E.D.

2In general, we have no strong a priori reason to believe whether the output demand and input supply uncertainty should be positively or negatively correlated. The convenient assumption of zero correlation is tantamount to taking the neutral position in the face of equal ignorance. Needless to say, the several results we will obtain rest on the zero correlation assumption and may not be generalized to cover the more difficult cases of non-zero correlation.

$3^{3}$ While the notion of a quantity demand response to a supply price signal is straightforward, that of a demand price response to a quantity supply signal poses a little difficulty. With regard to the latter, we may have to require the existence of some marketing or an intermediate trading agency that quotes a demand price to the firm's quantity offer. Such intermediate agencies might not exist for all markets. Wherever they do not exist, there is still a useful 
and interesting implication to be drawn (as we will later observe) by treating the quantity signalling behavior as a conceptual exercise.

${ }^{4}$ The argument in the preceding footnote applies here but in the context of the input market.

${ }^{5}$ The analysis quickly becomes complicated for the case where firms are risk-averse. Obviously, our results rest on the risk neutrality assumption and extensions to risk-averse firms await further analysis.

6 The arguments in the profit function $\pi(\cdot)$ for each oubsequent behavioral class are ordered in sequence to express the sequential steps by which each choice variable is made. For example, in $\pi(I, \theta, n, q, 0, \eta)$, I is chosen ex ante $(\theta)$ and $(\eta)$ whereas $n, q, 0$ are chosen ex post $(\theta)$ but ex ante $(\eta)$. Also note that the profit functions generally differ among behavioral classes. However, notational complexity makes it desirable to denote $\pi(\cdot)$ as the profit function which implicitly differs among behavioral classes according to the arguments contained within.

7 From now on, the notation for the solution follows the alphabetical order of indexing of each experiment. For example, the letter "a" is used to denote the solution in the $\left(n^{d}, q^{s}\right)$ behavior which is indexed under subheading "(a)".

8t should be noted that the firm is assumed to be risk averse in Baron [2] and Leland [4] but risk neutral in Iwai [3], Mills [8] and Lim [6].

${ }^{9}$ The proof of proposition 6.1 is straightforward and is contained in $\operatorname{Lim}[5]$. 
${ }^{10}$ Let $\gamma$ be a random variable and $x, y, z$ be decision variables affecting the pay-off functions $J(\cdot)$ and $J^{\prime}(\cdot)$. By Bleckwell's criterion,

$\left.\underset{x}{\operatorname{Max} E_{\gamma}[\operatorname{Max}} J(\cdot)\right] \underset{y, z}{\operatorname{Max}} E_{\gamma}\left[\operatorname{Max}_{z}^{\prime}(\cdot)\right]$

provided $J\left({ }^{\circ}\right)=J^{\prime}(\cdot)$. Otherwise, if $J(\cdot) \neq J^{\prime}(\cdot)$ then the above inequality does not necessarily hold. 


\section{REFERENCES}

[1] K. J. Arrow and R. A. Lind, Uncertainty and the evaluation of public investment decisions, Amer. Econ. Rev. 60 (1970), 364-378.

[2] D. Baron, Demand uncertainty in imperfect competition, Internat. Econ. Rev. 12 (1971), 196-208.

[3] K. Iwa1, The firm in uncertain markets and its price, wage and employment adjustments, Rev. Econ. Stud. 41 (1974), 257-276.

[4] H. Leland, Theory of the firm facing uncertain demand, Amer. Econ. Rev. $\underline{72}$ (1972), 278-291.

[5] C. Lim, Uncertainty and implicit contracts, Ph.D. Dissertation, Queen's University, February, 1978.

[6] C. Lim, The ranking of behavioral modes of the firm facing uncertain demand, Amer. Econ. Rev., in press.

[7] J. Marschak and K. Miyasawa, Economic comparability of information systems, Internat, Econ. Rev. 9 (1968), 137-174.

[8] E. S: Mills, Uncertainty and price theory, Quart. J. Econ. 73 (1959), 116-129.

[9] E. S. Phelps, et a1., 'Microeconomic Foundations of Employment and Inflation," Norton; New York, 1970.

[10] H. Raiffa, and R. Schlaiffer, "Applied Statistical Decision Theory," Harvard Univ. Press, Cambridge, 1961.

[11] P. A. Samuelson, The fundamental approximation theorem of portfolio analys is in terms of means, variance, and higher moments, Rev. Econ. Stud. 37 (1970), 537-542.

[12] G. J. Stigler, The economics of uncertainty, J. Polit. Econ. 69 (1961), $213-225$.

[13] M. L. Weitzman, Prices versus quantities, Rev. Econ. Stud. 41 (1974), 479-491. 